Pensar la comunicación - Estado de avance

Carlos J. Giordano

Question/Cuestión, Nro.70, Vol.3, diciembre 2021

ISSN: 1669-6581

URL de la Revista: https://perio.unlp.edu.ar/ojs/index.php/question/

IICom -FPyCS -UNLP

DOI: https//doi.org/10.24215/16696581e587

\title{
Pensar la Comunicación - Estado de avance
}

Thinking About Communication - State of Progress

\section{Dr. Carlos J. Giordano}

Editor

carlos.giordano@presi.unlp.edu.ar /

giordano@perio.unlp.edu.ar /

cjgior@gmail.com

En medio de la noche primera de la Pandemia, cuando todo era incertidumbre vestida de certeza ("quince días"), dialogamos con Alejandra Cebrelli.

Con el correr de los minutos y los días, la única certeza fue la fortaleza de lo que necesitábamos: mantener los canales abiertos, atentos.

A ese fueguito amigo se acercaron rápido Paula Porta y Gerardo Bianchetti. Poco ¡pero poco en serio, eh!- después y al trote, se sumaron Lila Luchessi, Fernando Irigaray, Miguel Mendoza Padilla, Roberto Marafioti, Malvina Rodríguez, Claudia Ardini, Nancy Díaz 
Larrañaga, Carla Avendaño Manelli, Alexis Burgos... amigxs, colegas, compañerxs, que sentimos juntos que, primero, teníamos que estar cerca y, luego, ahí nomás, haciendo lo que podemos hacer: pensar, pensar en qué hacer, y en qué hacer en comunicación.

Así salieron varias ideas que hoy tienen un punto de síntesis con este "estado de avance".

En principio acordamos en darnos fortaleza asociativa armando un Programa de Investigaciones Interinstitucionales. Así surgió el Acuerdo entre la Cátedra Latinoamericana de Narrativas Transmedia del ICLA (Instituto de Cooperación Latinoamericana) de la Universidad Nacional de Rosario, con la Cátedra Investigación Periodística de la Universidad Nacional de Avellaneda, con el Centro de Estudios en Medios y Comunicación, Departamento de Humanidades y Ciencias Sociales de la Universidad Nacional de Moreno, con el INCOPOS (Instituto de Comunicación, Políticas y Sociedad) que depende de la Secretaría de Extensión de la Universidad Nacional de Salta, con el IICom (Instituto de Investigaciones en Comunicación) de la Facultad de Periodismo y Comunicación Social de la Universidad Nacional de La Plata, con el IIPPyG (Instituto de Investigación en Políticas Públicas y Gobierno) de la Universidad Nacional de Río Negro, con el Programa de Investigación Tecnologías digitales y prácticas de comunicación/educación del Centro de Investigación Políticas Públicas en Educación, Comunicación y Tecnología de la Universidad Nacional de Quilmes y con el Programa de investigación "Comunicación institucional, política y mediática: prácticas: agendas, discursos, redes en comunidades y territorios. Segunda parte" de la Secretaría de Investigación y Extensión del Instituto Académico Pedagógico de Ciencias Sociales de la Universidad Nacional de Villa María.

El Programa tiene los siguientes fundamentos:

- Los procesos de investigación en temáticas de y sobre la transdisciplina Comunicación tienen un largo desarrollo en nuestro país. Con antecedentes confluentes, puede afirmarse que las búsquedas y las definiciones para crear los estudios universitarios específicos -allá por 1934 en La Plata y luego en cada punto del país federal hasta el presente- inauguraron prácticas de indagación sistemáticas, tendientes a la producción 
de conocimiento original, moderno y modernizador, es decir lo que hoy definimos como uno de los componentes principales de la Investigación.

- Estos procesos son -y han sido- heterogéneos en los objetos, productos y desarrollos. Han atendido desde muchos y variados enfoques, posicionamientos teóricos y procedimientos, el trabajo de "hacer" y -por lo tanto- así colaborar en construir el "campo" bourdieuano. No es correcto afirmar que es infinito e indefinible en los límites de sus alcances, pero sí que es eficazmente heterogéneo, ricamente entramado, finalmente reconocible entre nosotros y cada vez mejor por los "afueras" de los otros académicos, de los otros disciplinarios, de los otros que muchas veces somos nosotros mismos trabajando y produciendo en latitudes y longitudes epistemológicas bien acomodadas en los anaqueles de las disciplinas tradicionales (y aún en espacios interdisciplinarios de mucho prestigio y data).

- Asimismo, en todos y cada uno de los espacios formativos en lo que genéricamente se aúna bajo titulaciones de "comunicación", ya se han instalado Unidades de Producción de Conocimiento (Institutos, Centros, Laboratorios y otros con denominaciones diversas pero con objetivos precisos y pertinentes) que están en plenos procesos académicos reconocidos (de investigación, de divulgación, de gestión, de capacitación y de actualización, de formación de nuevos integrantes interesados, de propuestas a convocatorias macroinstitucionales, etc.).

Los objetivos se sintetizan en que:

- el Programa propone un espacio que acompañe y complemente a todos los que lo integren, en sus acciones y objetivos puntuales, a través de la construcción de herramientas conjuntas;

- podrá contener Proyectos de investigación sobre todas y cada una de las temáticas aceptadas y reconocidas del "campo",

- podrá impulsar presentaciones conjuntas ante convocatorias de Agencias financiadoras o propulsoras de la producción de conocimiento,

- podrá oficiar de aval y espacio de evaluación a iniciativas más individuales como Becas o presentaciones a subsidios, sin competir con ninguna instancia de las Instituciones (Carreras, Departamentos, Facultades, Universidades) que nos contienen formalmente, si no como un complemento potenciador. 
- sabemos que estas iniciativas no son sino producto de procesos de maduración complejos, que tienen que concurrir en instrumentos legales que las refuercen y definan con precisión;

- podemos ir probando la dinámica en uniones transitorias, en trabajos episódicos, que les den carnadura a lo que se hipotetiza en los planteos iniciales, iniciáticos; y

- estas "pruebas" no deben ser "como si" produjéramos, sino que deben permitir avanzar en construcciones concretas, avaladas por el trabajo de quienes las hagan, confrontadas con necesidades y prioridades acordables por las partes que asuman la circunstancia, en diálogo con objetivos -en este caso- macroregionales, preferiblemente nacionales y con verdadero énfasis federal.

Ahí mismo, casi, definimos cuatro (4) macroejes de discusión y más de 60 investigadores, docentes, estudiantes, becarios, tesistas, productores, en comunicación nos enviaron sus reflexiones sobre Infodemia, Brechas, Ciudadanías y Mediaciones.

A continuación, con esos aportes como disparadores, produjimos un encuentro por Eje, mediante reuniones sincrónicas virtuales, Conversatorios los llamamos y hubo más de cien compañerxs por encuentro.

Todo este proceso es consultable y recorrible en www.pensarcomunicacion.ar

Y ahora, al efecto de intervenir en este Informe Especial de Question/Cuestión “¿Cómo fue el futuro que vendrá?", armamos un collage "continuum" con intervenciones de varixs de Ixs nuestrxs... Digamos que es lo que en algunos momentos fue definido como "dar vuelta la cámara (y mirarnos, y escucharnos, y decir...)". Cada aporte es individual, sí. Pero tiene la potencia de su originalidad colectiva de pensamiento, de angustias saldadas, de prospectiva deseada, de planteos para que no volvamos a tener el mismo futuro que nos trajo hasta acá. 
- Mediaciones. Tiempo de crecer

Claudia Ardini

- Dicotomías en escenarios micro, meso y macro: la aceleración de emergencias y ausencias en Pandemia

Carla Avendaño Manelli

- $\quad$ Periodismo y comunicación de la ciencia en tiempos de pandemia Mariana Bonano

- Pensar la comunicación para la sociedad

Alfredo Caminos

- $\quad$ El rol de los medios universitarios en tiempos de pandemia Lucía Casajús y Mario Giorgi

- Hacia una comunicación plurinacional

Alejandra Cebrelli

- Desafíos de la pandemia a la comunicación

Silvana Comba

- La saludable desconfianza a los medios en tiempos de pandemia

Carlos Colombo

- $\quad$ Santa Cruz en la pandemia: Solidaridad a flor de piel

Alfredo Fernández

- $\quad$ Pensar la comunicación-educación en tiempos de A.S.P.O.

Alejandra María Gordillo

- Hibridaciones pospandémicas: Nuevos escenarios comunicativos

Fernando Irigaray

- Democracia, neoliberalismo y pandemia

Gabriel Lamanna 
- La infodemia solo es reversible con el ejercicio profesional del periodismo.

Lila Luchessi

- $\quad$ Estar juntos en pandemia (¿y después?)

Susana Martins

- $\quad$ El periodismo de investigación durante la pandemia

Miguel Mendoza Padilla

- Espacios, identidades y representaciones: El culto del Milagro en contexto de pandemia

Daniela Nava Le Favi

- Mediaciones en pandemia: Derecho a la Conectividad

Paula Inés Porta

- La pandemia de la desigualdad. Acerca de la comunicación y las brechas de género.

Malvina Eugenia Rodríguez.

- Desigualdad y pobreza en Salta: cómo impactó la pandemia en los sectores populares

María Natalia Saavedra

- $\quad$ Convergencias, transmedia y democracias

Una mirada a nuestras conversaciones sociales en la coyuntura política actual

Nadir Emanuel Secco

- La otra epidemia, la desinformación. El rol de los medios y los comunicadores frente a la pandemia

Pani Toledo

- Experiencia desde la Lic. en Comunicación Social de la Universidad Nacional de San Juan

Cecilia Vila 


\section{Mediaciones. Tiempo de crecer}

Claudia Ardini

cardini@unvm.edu.ar / claudiaardini@gmail.com

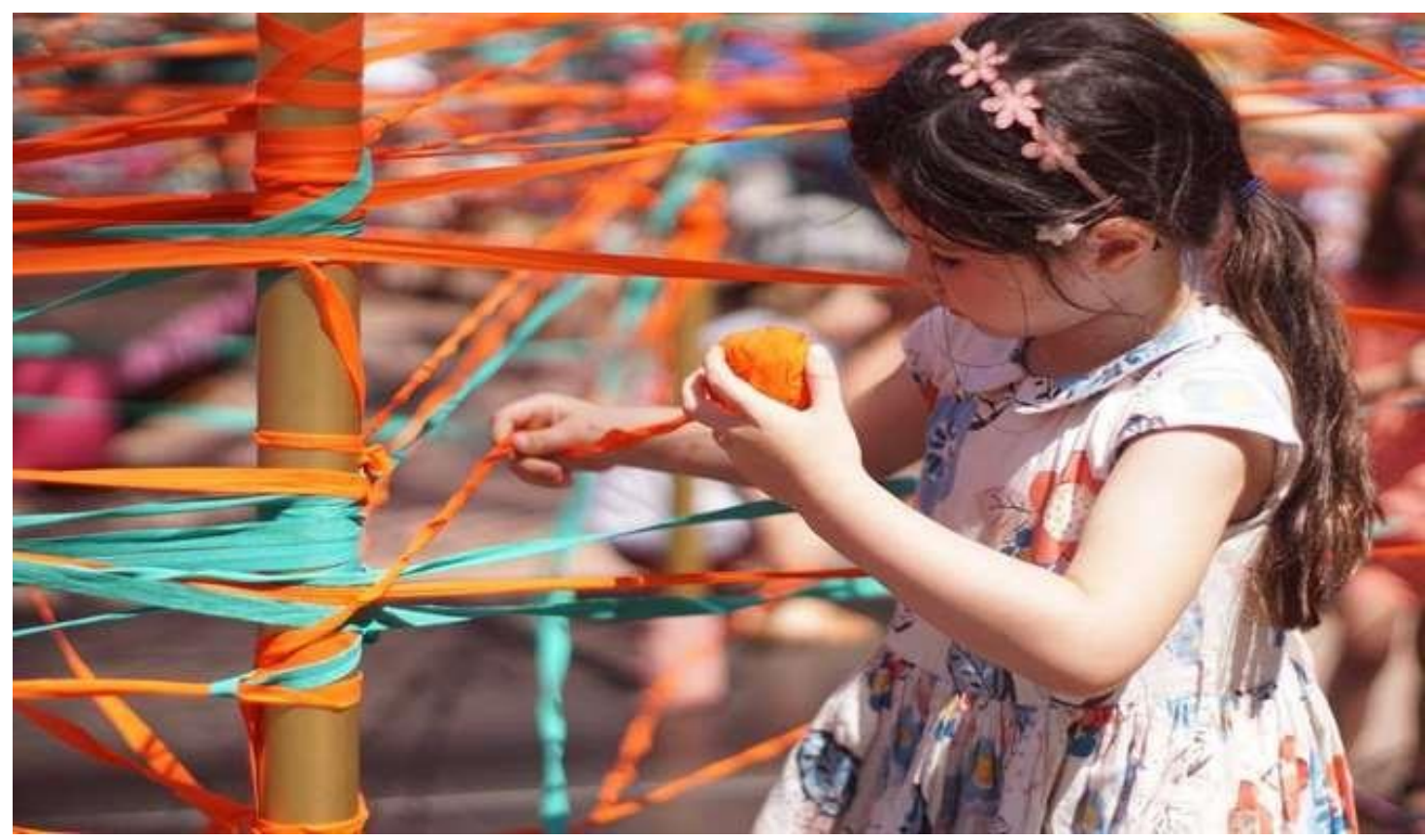

Foto: @TOTHOTORNOT

Nos quedamos huérfanxs. Sabíamos que más temprano que tarde eso iba a ocurrir. Fantaseamos con la idea de que siempre van a estar allí para calmarnos cuando el desasosiego nos gana. Sabemos que no es así. Igual preferimos no pensarlo. El tiempo, ajeno a nuestros deseos y temores, hace su trabajo en silencio. Nuestros padres envejecen y algunos hasta se empeñan en que no lo notemos, y siguen prodigándose como cuando éramos niñxs y nos abrían los ojos a mundos que no alcanzábamos a comprender pero que estábamos ávidxs de explorar. O como cuando en plena adolescencia nos señalaban caminos posibles a recorrer y con alguna soberbia nos atrevíamos a desconocerlos, porque bueno, para eso se es adolescente, para discutir a los padres. Crecemos y ya jóvenes vamos por nuestra propia 
experiencia. Nuestros padres bien, gracias, pero casi no tenemos tiempo en este presente para escucharlos. Ya somos adultos. Los padres siguen allí, los visitamos de vez en cuando, nos gusta hacerlo, pero tenemos apuro, así que ya, pasemos a otra cosa que las urgencias mandan. Los advertimos un poco cansados, pero están ahí como imágenes inmutables, eternos, pensamos. Nos preguntan y se preguntan por asuntos del tiempo en el que vivimos. Dejan, como al pasar, alguna puerta abierta por si nos queremos asomar a algo que están pensando. Nos dan señales por si acaso queremos y podemos detenernos a descifrarlas. Nos acercan la punta de algún hilo, quién sabe, quizás en algún momento necesitemos ir del ovillo a la madeja para volver a tejer la trama. Están allí y eso nos tranquiliza. Me pregunto por cuánto tiempo más. No lo sé. No lo queremos saber.

Y así, el día inefable llega. Un tuit de @Carlos Scolari anuncia la muerte de Jesús Martín Barbero. Lloro, mientras busco compartir con mis compañerxs (hermanxs) la noticia increíble. Lloro. A los padres se les llora cuando mueren. Lloro y percibo una orfandad compartida por muchxs en tiempos en que anhelamos ser cuidadxs. Lloro porque no necesitamos ninguna muerte más por estos días, pero menos aún necesitamos esta muerte, la de un padre cuando sus hijxs navegamos en un mar de incertidumbre.

Así estamos.

Se me perdonará la analogía, pero me resulta necesaria para dar continuidad a la breve reflexión que había presentado en el video para pensar la comunicación. Allí refiero a Jesús Martín Barbero (JMB) como uno de los autores más citados del campo de la comunicación y al mismo tiempo, uno de los pensamientos más difíciles de concretar en la acción, ese lugar único donde se acaba por comprender cabalmente cualquier concepto, idea o teoría sobre la que tematizamos en papers, clases o conferencias.

La estrategia de JMB, señala Amparo Marroquín, fue dejar de pensar la comunicación como teoría para pasar a entenderla como proceso, moverse de la reflexión del sujeto para ir a sus prácticas, pero sin plantear nuevas dicotomías; si no en una dialéctica en la que se construyen los procesos de subjetividad. $(249,2019)$ 
Es probable que la inercia nos lleve hacia otro lugar, lejos del deseado, cuando una lectura o una charla nos moviliza y nos impulsa a cambiar nuestras prácticas. Es probable que la dificultad para transformar estructuras como las educativas o las pertenecientes al sistema de medios de comunicación se deba al menos a dos razones. Por un lado, el fuerte arraigo en la cultura que alcanzan algunas creaciones humanas y la tendencia a no entenderlas como tales. A fuerza de deshistorizarlas y de naturalizarlas, se vuelven parte del paisaje.

Por otro lado, la articulación de estas estructuras al poder económico y político. La escuela, moldeada al calor de la sociedad industrial y del nacimiento de los estados nacionales, fue una herramienta muy eficaz para la formación de la ciudadanía que esos estados y las lógicas laborales de esa etapa del capitalismo necesitaban.

La comunicación materializada en los medios y dispositivos a través de los cuales fue evolucionando, particularmente en el siglo XX, recorrió, de algún modo, un camino análogo al de la escuela. No nos detendremos en este punto, pero basta decir que el modelo de broadcasting, predominante en el siglo pasado y hasta la primera década del presente, es elocuente en relación a lo señalado.

\section{Tiempo de crecer}

Así, con modelos educativos y comunicacionales de base jerárquica y elitista, la reflexión ha sido prolífica, pero los márgenes de acción/transformación, tanto en el campo de la educación como en el de la comunicación, han sido escasos. Afortunadamente, nada es tan lineal y de la mano de JMB otra vez ;) las mediaciones vinieron en nuestro auxilio para mirar a través de ellas el gradiente de colores que atraviesa a los procesos de comunicación en la cultura. Internet, las redes y la variedad de plataformas y dispositivos nos llevaron a hablar de hipermediaciones que velozmente mutaron en transmediaciones. Más acá, con algunxs compañerxs hablamos de inmediaciones para pensar en las conversaciones y territorialidades emergentes.

La perspectiva ecológica fue, entre otras, el caldo en donde cultivamos nuestras reflexiones en torno a la comunicación. Sentimos cierta comodidad allí. Estamos transitando la 
tercera década del siglo XXI. Tratamos de entrarle con nuevas lecturas. Algunas prácticas con intención innovadora se abren paso en medio de la maleza arraigada. Pequeños oasis en un desierto plagado de repetición. La pandemia del COVID-19 se nos presenta como lo inesperado en palabras de Edgar Morin. Incertidumbre es la palabra que nos atraviesa de cabo a rabo como individuos, como sociedad. No nos hizo mejores, solo nos dejó más desnudxs. Giramos al máximo la llave que logre abrir la puerta a la comprensión. Probamos varias, ninguna termina de hacerlo. ¿Qué nos está pasando? ¿Qué nos está faltando? ¿Será que algo en nuestro cerebro arcaico se empeña en evitar que en nuestras redes neuronales se active el olfato, la mirada, la piel necesarias para percibir el sensorium de este tiempo? ¿Será que además de comprender ese sensorium se nos hace imprescindible habitar la experiencia? La nuestra y la de las otras y otros. La praxis. Hacer, comunicar, educar, trabajar, comprender con, no para otrxs, como hace algunas décadas nos enseñaban Freire y Kaplún. Si la imagen más representativa y simbólica de este tiempo es la red, tal vez tendremos que pensar que no existe tal llave porque ya no hay una puerta. Son otras y múltiples las entradas que tendremos que buscar. Tal vez las encontremos juntxs eligiendo y tejiendo los hilos de esa red que en cada nudo catalice los sentidos diversos de los que estamos hechos, de los que está hecho este tiempo. Cada nudo en la red puede servir para cristalizar viejos sentidos, saberes o prejuicios que clausuran el diálogo y la comprensión entre generaciones, etnias, estamentos, países o sociedades. Así está ocurriendo. Pero puede ser también que cada nudo sea una entrada entre muchas, a la que nos asomemos para conocer, para entender, para amar, para hacer, para enseñar, para aprender, para comunicar.

"No debemos repetirlo -dice Amparo Marroquín- la única forma de continuar la tradición Martín-barberiana es revisar las nuevas mutaciones que mueven el mapa hasta volverlo inimaginable, unir los puntos, con los números, con las preguntas que ahora nos habitan." (2019)

"(...) voy tratando de crecer y no de sentar cabeza" canta Baglietto y la tarea, además de multiplicar, es hacernos grandes de una vez. Ningún padre, ninguna madre vendrá ya a auxiliarnos. Sus palabras servirán si podemos traducirlas al tiempo por venir, si podemos hacer/tejer con las palabras, las suyas, las nuestras, con otros, otras y otrxs las redes que por 
Question/Cuestión, Vol. 3, Nº70

Diciembre 2021

ISSN 1669-6581

contenernos también nos transforman y hacen que este mundo que está siendo así, como anunciaba Paulo Freire, pueda ser de otra manera.

Claudia Ardini. Profesora e investigadora. Universidad Nacional de Córdoba. Universidad Nacional de Villa María. 


\section{Dicotomías en escenarios micro, meso y macro:}

la aceleración de emergencias y ausencias en Pandemia.

Carla Avendaño Manelli

La pandemia aceleró la reconfiguración de los espacios privados, organizacionales y público. Diluyó fronteras entre la intimidad y formalidad laboral. Genero nuevos escenarios organizacionales. Aceleró disputas en las narrativas mediáticas de la realidad.

\section{Micro: El "adentro" y los "afuera (s)"}

A las 08:33 de hoy... he leído cinco diarios: nacionales, provinciales y locales... además de portales de noticias; conozco la temperatura y el pronóstico de todo el país; voy respondiendo casi veinte whatsapps y dos Telegram; estoy subiendo contenidos al aula virtual; programando encuentros sincrónicos con mis estudiantes por Meet; pagando impuestos y servicios por home banking; sacando turno por "Ciudadano Digital" para la segunda dosis de la vacuna; cargando datos en CVAr, viendo publicaciones en Instagram y en Facebook (sí, tengo más de 40 años), que me notifica el cumpleaños de un conocido; también abro las tres cuentas de Mail porque ya vi desde el celular que me ingresaron correos institucionales; estoy inscribiéndome a un congreso virtual; viendo algún regalo... se hicieron las 9:34.

Aún no salí de mi casa. Sin embargo, sé cuál es el estado del tiempo y me abrigo en consecuencia a la precisión meteorológica, pese a no sentir en mi cuerpo la temperatura... La agenda me avisa que a las 10.00 tengo clases... VIRTUALES

Desde la particularidad de mi espacio doméstico me inserto en los "multiversos" laborales, profesionales, institucionales, mercantiles, fiscales, locales, regionales, nacionales e internacionales. Como un holograma se expande mi ser en un tiempo / espacio que, por mi 
concepción generacional de esos cuadrantes cartesianos, ha oscilado por momentos de crisis estructural y adaptación darwiniana. En fin: ni yo, ni mi entorno somos los mismos.

\section{Meso: Los aprendizajes: de las resistencias a las adaptaciones}

Los establecimientos (físicos) que materializan la satisfacción de las necesidades sociales, públicos, privados con y sin fines de lucro, reconfiguraron su complejidad sistémica por una supra complejidad que incorporó, no siempre sin resistencias, múltiples acciones digitales que reconfiguraron, tanto el entono organizacional como a las organizaciones en sí mismas.

\section{Macro: Catálisis: entre Fake News y Debates Éticos}

La Pandemia y sus consecuencias: medidas y políticas en relación al aislamiento, protocolizaciones, vacunación, contagios, muertes, debates de salud pública, de economía, entre tantos, aceleraron los procesos de mediación digital en las mediaciones sociales.

La percepción de la realidad, como nunca se construyó alrededor de medios: "tradicionales" y consolidando, "nuevos". La imperiosa distancia con la dimensión vivencial (material) de la cotidianeidad, la necesidad y el derecho humano de estar informados propiciaron la catálisis de la, ya acostumbrada, contienda entre poderes hegemónicos y contra poderes, en una cancha que evidenció la falsa construcción de acontecimientos y su contra ofensiva, promoviendo serios debates éticos entre diversos actores de la comunicación.

Carla Avendaño Manelli. Docente, investigadora y coordinadora de la Licenciatura en Comunicación Social de la Universidad Nacional de Villa María. 


\section{Periodismo y comunicación de la ciencia en tiempos de pandemia}

Mariana Bonano marbonan0593@gmail.com

Universidad Nacional de Tucumán/CONICET

Pensar la relación entre la comunicación de la ciencia y el avance del conocimiento científico en los tiempos actuales, implica retornar a algunos de los principios éticos que están en la base de la profesión periodística no exclusivamente dedicada al abordaje de problemas científicos. La ética en tanto reguladora de la práctica informativa(1) se vincula antes bien con aquel tipo de investigación que Mario Bunge ha denominado "ciencia aplicada" y "tecnología" para distinguirla de la "ciencia pura o básica", aquella que involucra a investigaciones cuyo fin es "obtener conocimiento de un determinado sector de la realidad, sin otro interés que el de enriquecer el bagaje del saber de la cultura" (Laso, 1996: 35). Son justamente los asuntos asociados con la ciencia aplicada y la tecnología entendida en tanto "uso de las teorías científicas para su adaptación a determinados fines, a la producción de artefactos útiles" (36), los que orientan la búsqueda de posibles aplicaciones prácticas a problemas de interés social; en ese sentido, aduce Eduardo Laso (1996), la ciencia aplicada no es libre de elegir sus objetos de estudio puesto que estos últimos surgen de las necesidades de la población. Los problemas asociados a la salud o al crecimiento económico y productivo de un país se circunscriben justamente al tipo de conocimiento científico puesto al servicio de la intervención o transformación concreta de la realidad; constituyen al mismo tiempo el sector de la ciencia al que los medios de comunicación prestan mayor atención, particularmente en momentos donde informar sobre la salud de la población mundial adquiere prominencia porque condiciona las actividades socioeconómicas y políticas en un mundo globalizado.

Como advierte la bibliografía (Díaz, Laso, Vara), la comunicación científica no deja de estar mediada por intereses ideológicos y económicos que también atraviesan el ámbito

\footnotetext{
IICom (Instituto de Investigaciones en Comunicación) 
específico de la ciencia y particularmente, el de la ciencia aplicada definida en los términos explicitados más arriba. Si bien como puntualiza Laso a partir de la conocida expresión de Francis Bacon en el siglo XVII, "El saber es poder" -consigna que está en la base misma del nacimiento de la ciencia moderna-, el escenario actual plantea una reconfiguración de la ciencia asociada a la lógica capitalista y a la voluntad de dominio de la naturaleza. En esta dirección, se advierten dos movimientos que Laso (1996) señala en relación con el conocimiento científico: por una parte, la subvención por parte de las empresas, de investigaciones que redundan de modo directo en la obtención de productos lucrativos; y por otra, la creación de fundaciones de investigación que en un principio despliegan una "ciencia pura" pero cuyo desarrollo a la larga tiene por fin impactar en una innovación rentable. La lógica económica termina subsumiendo entonces al conocimiento científico, el que se pone al servicio de un poder legitimador del saber.

La tendencia a la dominación de los objetos y saberes científicos por parte de las fuerzas económicas que hegemonizan el orden social, tiene su paralelismo en el universo mediático globalizado actual. Al respecto, Manuel Castells afirma que en los medios se verifican las mismas tendencias generales que han transformado al mundo empresarial: globalización, digitalización, creación de redes y desregulación (Citado en Vara, 2015). Respecto del periodismo científico en particular, Ana María Vara, periodista científica e investigadora del Centro de Estudios de la Ciencia José Babini (UNSAM), expone que este sector de la práctica informativa no está exceptuada de los nuevos modelos de negocio prominentes en el presente, derivados de la transformación que supone la introducción de las nuevas tecnologías. Al respecto se pregunta por la rentabilidad de empresas periodísticas dedicadas a la cobertura de notas científicas y al mismo tiempo, por las noticias de ciencia en la era de la distracción, cuando predomina una ecología de los medios atravesada por internet y su lógica fragmentaria. ¿Y el periodista científico cómo se ubica en esta nueva reconfiguración del paisaje mediático?

El contexto de la pandemia acarreada por el Covid 19 y sus derivas a nivel global, puso en foco la comunicación sobre aspectos troncales de la investigación científica ligada a temas de salud. En particular, se requirió en los medios la palabra de expertos médicos epidemiólogos, infectólogos- así como de investigadores que trabajaban en pos del 
descubrimiento de una cura para la enfermedad o bien, de una vacuna tendiente a prevenirla. Pero también esta situación dejó al descubierto el acceso a una proliferación de fuentes dispersas y diversas que permite dar cuenta del fenómeno que Marshall Mc Luhan denominó "salto de escala", esto es, un salto radical que según advierte Vara (2015), se corresponde con la idea de "pregnancia", el tiempo que tarda un medio en difundirse en una proporción significativa de la población. Frente a ello, se pregunta Vara (2015), ¿cuál es el valor que adquiere la nota del/la periodista científico/a en la medida en que se desdibuja la noción de periodismo al ponerlo en la misma categoría que textos de servicio, de entretenimientos, de publicidad encubierta y también de operaciones mediáticas cuyo propósito es el control de la opinión pública por parte de grupos económicos que compran medios para defender sus negocios?(2)

Hasta el presente, considera Vara (2007), el periodismo científico y médico no ha tomado conciencia cabal de la importancia de su papel en este complicado escenario: (...), además de ser fuente de información directa del público, es también fuente de información de los médicos, de las autoridades regulatorias y hasta de los propios expertos. Está demostrado que, en los países centrales, la aparición en los medios masivos -diarios de referencia, en especial, pero no solamente- aumenta el índice de citación de los artículos científicos publicados en revistas con referato. En nuestro medio, observaciones informales muestran que la aparición en los medios puede ayudar en la obtención de fondos (en particular, de fundaciones o actores privados). También puede verse que la aparición reiterada en los medios en relación con temas científicos o educativos de alto perfil -clonación, o la crisis de la educación- se correlaciona muy bien con saltos hacia posiciones de alta gestión de destacados científicos: presidencia de la Agencia Nacional de Promoción Científica y Tecnológica o rectorado de la Universidad de Buenos Aires, por ejemplo. (197)

En líneas generales, afirma la autora, la forma predominante del periodismo está todavía más orientada hacia la difusión de información sobre investigaciones científicas y tecnológicas que a la interpretación de los significados, alcances, límites y consecuencias de las mismas. Los conflictos de intereses, las controversias científicas, las investigaciones parciales o no concluyentes $y$, también, la investigación reñida con la ética, tienen una presencia mucho menor en el perfil de la agenda periodística (SECYT, 2006: 40). 
Por ello, para alcanzar un periodismo científico de calidad, la tarea pendiente en nuestro país es siguiendo a Vara (2015), vincular más estrechamente la práctica profesional del periodismo científico con la investigación en comunicación pública de la ciencia y más ampliamente, con los estudios sociales de la ciencia y de la tecnología. En este sentido, acordamos con la autora en que son pocos los periodistas científicos en nuestro ámbito que saben algo de nuestras instituciones científicas, o los que se atreven a escribir sobre política científica desde un lugar que no está atravesado por conflictos de intereses ligados a los grupos mediáticos que integran o bien, por presiones tanto del sector público como privado. (3) Se trata de una situación compleja que no admite soluciones apresuradas pero que requiere en primera instancia, la toma de conciencia por parte del comunicador sobre ciencia de que los conflictos de interés existen y se deben manejar de manera que no afecten la credibilidad y la calidad de la noticia frente al público (Vara, 2015).

Más allá de la posición conflictiva antes detallada del periodista que cubre temas de ciencia, tecnología y salud, la situación del informador en saberes y conocimientos científicos puede mejorar si aquel piensa su práctica no tanto -o no tan solo- como el ejercicio de un mero divulgador de avances o de datos proporcionados por los investigadores médicos 0 sanitaristas, si no en los términos de un actor central en la tarea de prevención, esto es también, un protagonista activo en la investigación centrada en la obtención y contrastación de fuentes confiables para la construcción de la nota sobre ciencia. Su credibilidad cobrará fuerza en la medida en que sea capaz de ejercitar su profesión desde una ética que contribuya a la democratización del conocimiento especializado, al colocar en contexto los datos científicos proporcionados y evidenciar así una conciencia crítica que aporte a dar cuenta de los intereses económicos y políticos concomitantes a la conformación de la cultura científica de toda sociedad.

\section{Bibliografía citada}

Díaz, Esther (ed.) (1996). La ciencia y el imaginario social. España: Biblos. 
Laso, Eduardo (1996). "La clasificación de las ciencias y su relación con la tecnología". En Esther Díaz (ed.). La ciencia y el imaginario social. España: Biblos. 29-40.

Vara, Ana María (2007). "Periodismo científico: ¿Preparado para enfrentar los conflictos de interés?". Revista CTS, no 9, vol. 3, agosto. 189-209.

Vara, Ana María (2015). "Periodismo científico. Entre la profesionalización y los desafíos del cambio tecnológico". En Susana Espinosa (comp.). Ciencia, arte y tecnología. Enfoques plurales para abordajes multidisciplinares, Libro I. Buenos Aires: Universidad de Lanús. 165185.

\section{Notas}

(1) Desde el punto de vista filosófico, la ética se distingue de la moral, esta última más ligada al plano normativo en tanto conjunto de normas, costumbres y tabúes que regulan las relaciones entre los sujetos y que varían según el contexto histórico-social. La ética o deontología profesional incumbe en cambio a los comportamientos y pautas de actuación que los profesionales de un sector determinado sector ponen en práctica para el ejercicio de su labor.

(2) Entre otros ejemplos proporcionados por la autora respecto del periodismo científico en Argentina, menciona la cobertura de la cirugía de tiroides de la por entonces presidenta Cristina Fernández en enero de 2012. Puntualiza que en un primer momento, el grupo Clarín pretendió hacer creer que había sido una operación de prensa por parte del Poder Ejecutivo la difusión del diagnóstico de cáncer. Pero fue una periodista científica del propio diario Clarín quien echó por tierra esa maniobra. Mostró que "el diagnóstico que había hecho público el vocero de la Presidencia era el que correspondía a partir de los estudios realizados, y que se debía a una situación estadísticamente poco frecuente que el diagnóstico de cáncer no se hubiera confirmado tras la cirugía" (Vara, 2015: 182). Ejemplos de operaciones mediáticas similares podemos encontrar a lo largo de este año y medio de pandemia en relación con la política presidencial y su rol en el manejo de la salud pública y la consecución y administración de las vacunas contra el Covid 19. 
(3) Vara (2007) da cuenta del caso argentino, donde de manera rutinaria los periodistas científicos son invitados a congresos y todo tipo de actividades por parte de empresas, que se aseguran la cobertura del tema que les interesa -lo cual tiene que ver con alguno de sus productos. $Y$ ofrece como ejemplo los lanzamientos de estudios sobre una nueva droga o un tratamiento terapéutico, que se realizan en el marco prestigiosos congresos, muchos de los cuales son organizados en las ciudades más atractivas del mundo, como París, Florencia, Berlín, Nueva York, entre otras. 


\section{Pensar la comunicación para la sociedad}

Alfredo Caminos

alfredocaminos@artes.unc.edu.ar

En el año 2020 el planeta se despertó con un virus que cambió las estrategias de socialización, las formas de comercialización, las maneras de viajar y relacionarse, y también la comunicación, y cómo aprender y cómo enseñar, y en un sentido más estricto, "qué" enseñar. Como si la tecnología permitiera olvidar lo que pasa alrededor mientras estamos conectados al mundo por diversos aparatos y pantallas.

La extensión de la situación pandémica se mantiene a la espera de lo que resulta ya habitual con las enfermedades, que una vacuna disminuya los riesgos de contagios y aumente la posibilidad de continuar con la vida más o menos como era antes, sin barbijo, atendiendo los pocos o muchos casos y tender a erradicar la enfermedad. Para beneficio de la economía, lo social, lo religioso, la política, la educación. Esa es la normalidad, una sociedad tratando de adecuarse a las consecuencias de una catástrofe, de una guerra o de una pandemia. Como ha sido siempre. En el caso particular de la comunicación, resulta de fundamental relevancia pensarlo en términos de conjunto social y de actuación como un entramado. Sociedad con comunicación es un conjunto con progresión y adecuación. En la vereda de enfrente estaría la gestión, no por contrario sino como una modalidad necesaria y directa. De todas maneras, una sociedad articulada e inmersa en la gestión consigue una sociedad diferente; pero la solución no siempre puede resultar en una mejora o un progreso. Es la comunicación paralela o contra la gestión la que da la posibilidad de progresar, de socialización y de educación.

Las palabras claves del momento cúlmine de la pandemia fueron: restricciones, encierro, testeos y quedarse en casa. La comunicación debería haber sido motor del funcionamiento de la sociedad, sin embargo, quedó, en términos generales, en la educación y la información de los medios. La nueva situación pospandemia, que de momento convive en Argentina con la segunda ola y que se adaptan a nuevas modalidades de convivencia con muchos contagios y vuelta a la actividad, tiene como palabras claves a vacunas y vacunación, 
economía, fútbol, teatros y cines, vacaciones y presencialidad educativa. Ahora sí, comunicación se articula con la sociedad. Sociedad con comunicación para regresar a la normalidad o nueva normalidad. En resumen, no hay posibilidad de regresar a un estadío parecido al anterior sin comunicación. Es de esperar, obviamente, que la comunicación actúe ahora con el progreso social.

Dr. Alfredo Caminos Facultad de Ciencias de la Comunicación - Universidad Nacional de Córdoba 


\section{El rol de los medios universitarios en tiempos de pandemia}

Lucía Casajús

lcasajus@undav.edu.ar

Mario Giorgi

mgiorgi@undav.edu.ar

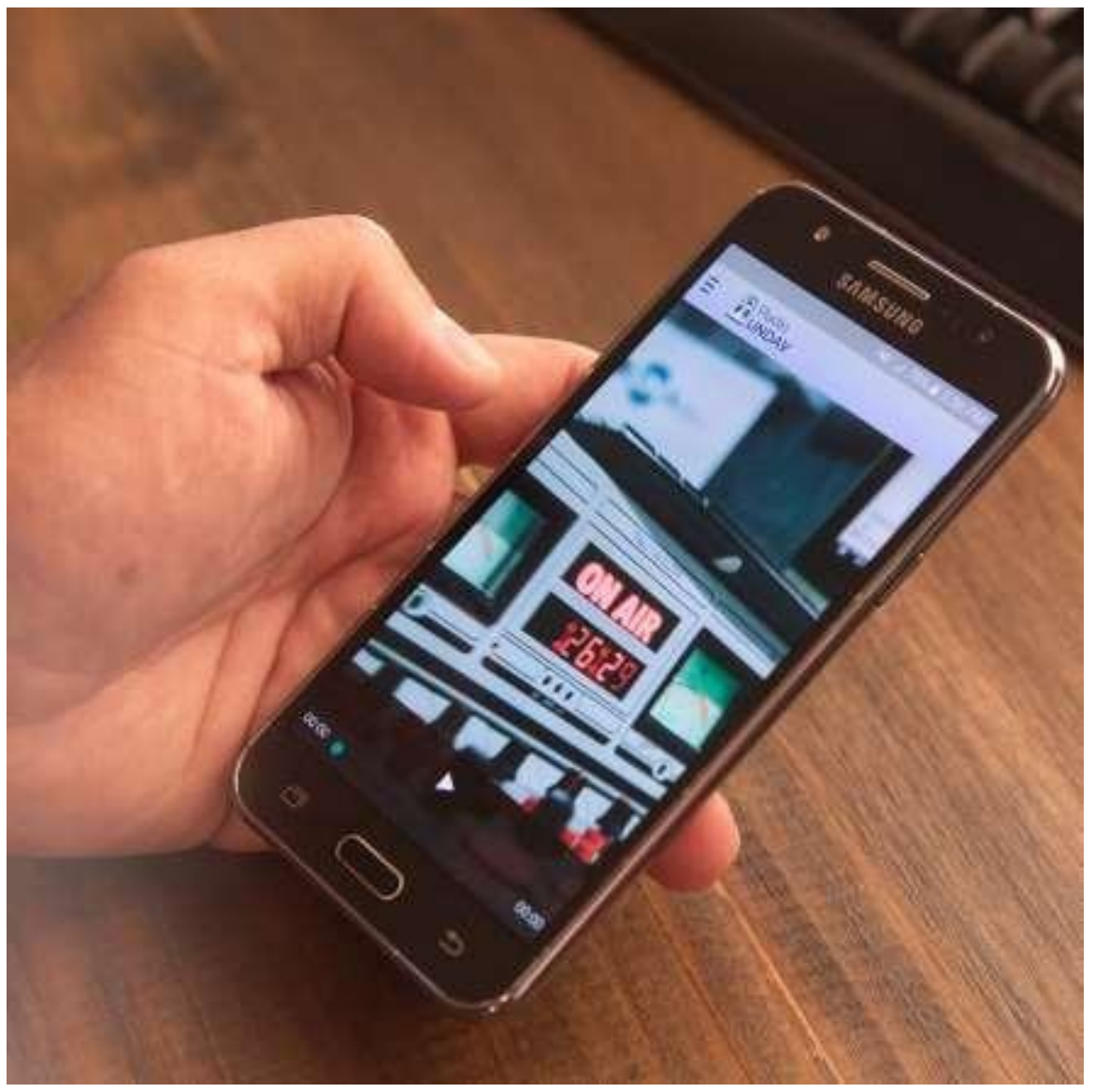

Lautaro Federico - Dirección de Medios - UNDAV 
La pandemia del COVID-19 ha generado múltiples análisis, debates, cambios y adaptaciones en todos los ámbitos de la vida y también en los medios de comunicación. En un escenario marcado por la Infodemia, entendida como la sobreinformación, la información inexacta, la sobreabundancia informativa y la circulación de noticias falsas, la tarea de los medios de comunicación universitarios es central, como espacios de comunicación alternativa que trabajan desde la universidad hacia la sociedad.

En este sentido, los contenidos informativos y la función de servicio público, son siempre un vector fundamental de los medios universitarios que, al mismo tiempo, deben garantizar los contenidos vinculados a la educación y la divulgación científica, así como los bienes culturales y la participación y la puesta en valor de la palabra de la comunidad universitaria.

Refiriéndonos a nuestra experiencia desde la Dirección de Medios de la UNDAV, adaptamos las programaciones de la radio y la televisión, sin las producciones habituales por falta de acceso a los estudios, y dispusimos algunas acciones para garantizar la difusión de aquellas producciones de la comunidad universitaria enviadas por quienes integran las grillas así como la emisión de contenidos especiales a partir de material de archivo. A lo que se sumó la realización de transmisiones y retransmisiones especiales en vivo; así como la puesta en marcha de nuevos programas realizados integramente mediante teletrabajo.

Todo ello, pgestionando los medios de comunicación universitarios en su doble vertiente, no solo como herramientas de comunicación, sino también como espacios que conjugan un fuerte compromiso con la educación y el aprendizaje, una función de servicio público con responsabilidad periodística y compromiso social. Que garantizan la apertura a la participación de toda la comunidad universitaria, que visibilizan temas y actores tradicionalmente invisibilizados por los medios hegemónicos, permitiendo un tratamiento diferente y en profundidad, no solo de las actividades universitarias sino también de los temas coyunturales de actualidad informativa, en este caso, vinculados a la pandemia.

Así, nuestros medios siguieron al aire con contenidos especiales y programaciones en emergencia, a través de Internet y las redes sociales, informando, comunicando, concientizando, difundiendo bienes culturales y garantizando el derecho a la educación, a partir 
de las fuentes oficiales y científicas; e incluyendo las voces de estudiantes, docentes, investigadorxs, trabajadores de la universidad y actores de la comunidad.

En el marco de la comunicación hegemónica, la tarea de los medios de comunicación universitarios es de gran importancia en el tratamiento de temas invisibilizados durante la pandemia, la consulta de fuentes oficiales y científicas frente a la Infodemia, y la elaboración de contenidos de servicio público, como espacios de comunicación alternativa, que trabajan con responsabilidad y compromiso social desde una mirada inclusiva, democrática y alternativa.

Lucía Casajús - Dirección de Medios de la Universidad Nacional de Avellaneda - Responsable de articulación institucional y académica en la Dirección de Medios de la Universidad Nacional de Avellaneda. Doctora en Comunicación y Magíster en Periodismo Digital y Multimedia (Universidad Jaume I, España). Lic. en Periodismo y Comunicación Social (UNLP). En su trayectoria profesional se ha desempeñado en medios de comunicación universitarios en Argentina y España. Su línea de investigación se ha centrado en la radio universitaria.

Mario Giorgi - Dirección de Medios de la Universidad Nacional de Avellaneda - Director de Medios de la Universidad Nacional de Avellaneda (UNDAV). Vicepresidente institucional de la Radio Internacional Universitaria (RIU). Locutor Nacional (ISER) y maestrando en Periodismo por la Universidad Nacional de Buenos Aires (UBA). Actualmente conduce el programa Radio País por Radio Nacional junto a Federica Pais. Fue Director Ejecutivo de RNA. Es autor de los libros Perfiles en la UNDAV. Conversaciones en la radio de la universidad (2015); La radio universitaria. Hacia una consolidación autónoma de medios (2015); y Un canto a los 40. Conversaciones en a radio de la universidad (2017). 


\section{Hacia una comunicación plurinacional}

Alejandra Cebrelli

alecebrelli@gmail.com

Universidad Nacional de Salta

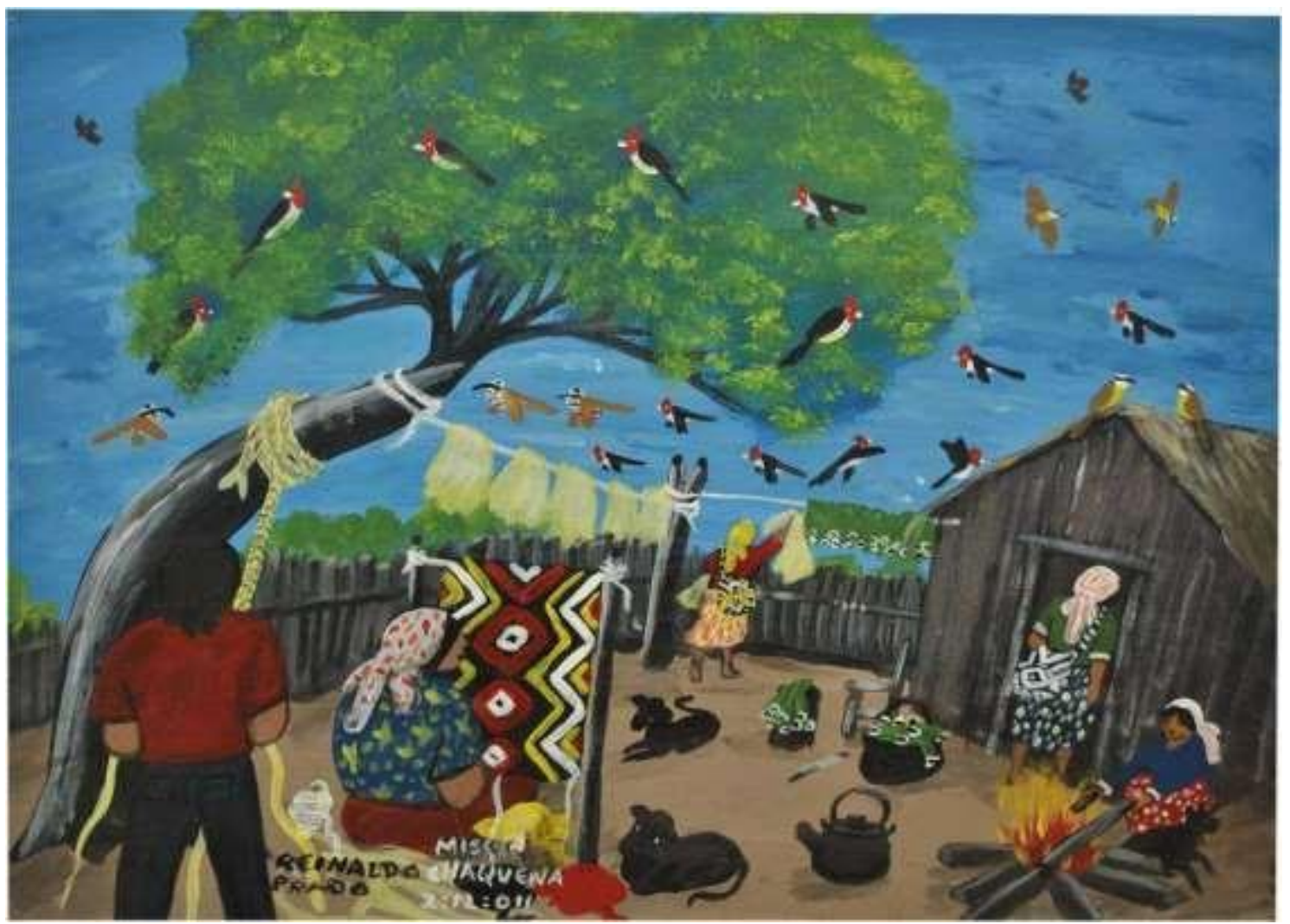

Reinaldo Prado https://www.facebook.com/search/top/?q=arte\%20y\%20esperanza

Hace un año, propuse la necesidad de pensar una comunicación plurinacional, categoría tomada de las mujeres indígenas que imaginan de manera muy otra el país siempre representado como homogéneo desde el imaginario oficial y desde un ecosistema mediático 
cada vez más concentrado e individualista, el cual borra las diferencias culturales al englobarlas bajo ciertas condiciones de exclusión, naturalizando estigmas e invisibilidades. Ello muestra un indudable avance de los sistemas de representación neoliberal, en circulación y legitimación creciente tanto en la cultura popular-masiva como en los imaginarios populares. Me interesa, por tanto, centrarme en algunas respuestas que pueden acercar la comunicación y el periodismo, focalizando la mirada en las naciones originarias.

Entiendo que la comunicación implica una puesta en común no exenta de las pujas distributivas por el poder simbólico. Por ello, una comunicación inclusiva debe apoyarse en la escucha activa de estas voces y en el entramado de sus narrativas con las oficiales. Así valores y representaciones 'otras' formarán parte de historias explicativas desde donde se puedan construir políticas públicas orientadas a la solución de problemáticas de estos actores subalternizados cuya diversidad pasa desapercibida por el funcionamiento de la imagen de un país uniforme y eurocentrado.

Carecemos de prácticas periodísticas que posibiliten informar sobre estas naciones, sin caer en miradas cristalizadas, sostenidas en más de doscientos años de discriminación y genocidios de alta o baja intensidad que no han cesado. Esta profunda grieta se asienta en el desconocimiento de las culturas y lenguas originarias, resultado de un racismo y un centralismo metropolitano macados a fuego en el ADN nacional aún no superado.

Entonces, ¿cómo realizar estas coberturas evitando formas de folclorización o de espectacularización de conflictos tales como las muertes por desnutrición, las innumerables formas violencias que sufren y la exclusión de derechos básicos? ¿Cómo informar sobre sus estrategias de 'asalto' al espacio público, sus saberes ancestrales que incorporan comunidad, vida, espiritualidad y territorio?¿Cómo chequear cualquier tipo de información desconociendo lenguas, modos y ritmos particulares de habla? ¿Cómo hacer llegar sus voces al espacio público de un modo legítimo y audible sin que las silencie la enunciación mediática sostenida en valores de venta y consumo?

La construcción de una comunicación plurinacional es una apuesta a la democratización plena de la comunicación. Incluye algunos desafíos iniciales: desnaturalizar el 
'sentido común, cada vez menos solidario; incluir en la enseñanza y en las prácticas periodísticas saberes sobre las raíces culturales de esta Argentina tan diversa.

El tratamiento de la información sobre los dolores y fortalezas de estas naciones se apoya en un periodismo de calidad: chequeo de datos, contextualización en cada cultura, respeto por los límites de lo decible y mostrable según sus costumbres, uso de categorías nativas para obviar las nominaciones estigmatizantes, inclusión de sus noticias en los temarios de las agendas...

La comunicación plurinacional implica un largo camino a recorrer, orientado a la inclusión en equidad estas voces en el espacio público para construir una Argentina multicultural desde matrices propias y decoloniales.

Dra. Alejandra Cebrelli - Semiótica, Análisis del Discurso, Medios -Categoría de Investigador 1 (CONEAU) Carrera de Ciencias de la Comunicación, Universidad Nacional de Salta 


\section{Desafíos de la pandemia a la comunicación}

Silvana Comba

silvanacomba7@gmail.com

Universidad Nacional de Rosario

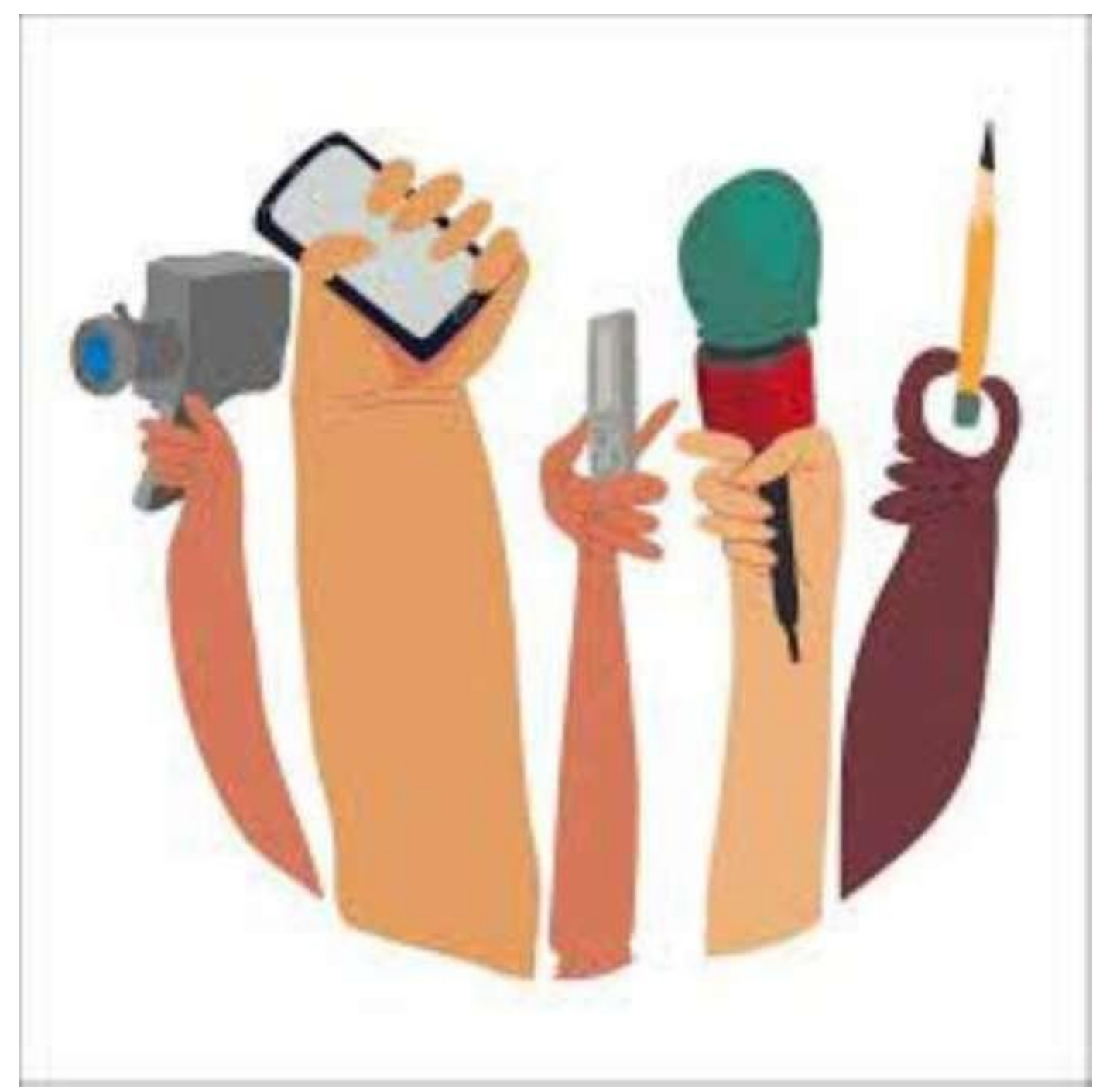

IICom (Instituto de Investigaciones en Comunicación)

Facultad de Periodismo y Comunicación Social

Universidad Nacional de La Plata 
La pandemia desafió los modos en que nos organizamos como sociedad. Y no es la primera vez que esto sucede. Pero sí es la primera pandemia que transitamos en la sociedad de plataformas. En una ecología de medios donde la comunicación y la buena gestión de grandes volúmenes de información son decisivas para coordinar acciones colectivas, para explicar claramente cómo tenemos que manejarnos con los cuidados preventivos, para sensibilizarnos y para ser solidarias y solidarios con los grupos más vulnerables de nuestra comunidad. Ahora también se pone en evidencia, más allá del sistema sanitario, la prioridad de lo público en la organización de la economía y la sociedad y la necesaria presencia del Estado. La comunicación no es la excepción. Un ejemplo de esto es la decisión que adoptó el gobierno nacional de declarar como servicios esenciales y estratégicos a la telefonía móvil, la conectividad a Internet y la televisión.

Como lo expresábamos en REDCOM, "hoy, los derechos a la educación, a la cultura, al trabajo y a la libre expresión, entre otros, se ejercen en su mayoría mediados tecnológicamente. $Y$ para eso se utilizan servicios comunicacionales que son prestados en condiciones monopólicas en algunos casos, oligopólicas o con profundas asimetrías y con una enorme inequidad de calidad, costo y alcance." En este contexto de pandemia, la comunicación a escala global, pero también regional y local, cobró más protagonismo, por supuesto con tensiones y dilemas por resolver. Sabemos que, a mayor escala del capitalismo, mayor influencia de la comunicación mediada. Somos conscientes de los problemas que acarrea la infodemia, las fake news, los discursos de odio en las redes. $Y$ ahí las comunicadoras y comunicadores tenemos mucho trabajo por hacer. Porque hay otras alternativas posibles y necesarias que, desde una perspectiva crítica, podemos desarrollar como estrategia a la hora de pensar la ciudadanía, la comunicación, la cultura, la política. Más aún, en un contexto como éste, donde la calidad de la información que consumimos y producimos, compartimos, hacemos circular en los medios sociales, se convierte en un factor clave para transitar la pandemia. En este escenario creemos que hay dos tipos de comunicación que cobran mucha importancia: la comunicación pública y la comunicación popular, comunitaria. El coronavirus es político, como plantea Mon Rodríguez: "El peligro va más allá del contagio viral de persona a persona, y va tomando forma en lo gubernamental, en las regulaciones, en la legitimidad de lo permitido y en los acuerdos que somos capaces de lograr para definir el tipo de sociedad y de vínculos que queremos." 
Silvana Comba, Universidad Nacional de Rosario. Licenciada en Comunicación Social, UNR, y Magister en Comunicación Social, Universidad Diego Portales. Profesora Titular de Comunicación Estratégica II y el Seminario Ciberculturas, en la carrera de Comunicación Social de la UNR. Directora de la Escuela de Comunicación UNR. Codirectora del Observatorio de Medios de la Facultad de Ciencia Política y RRII. Coeditora de la Revista Medios y Enteros. Investiga sobre ciberculturas, consumo y producción cultural en medios sociales.

@8daysaweekSil - instagram.com/silvana_comba - facebook.com/silvana.comba.5/ 


\section{La saludable desconfianza a los medios en tiempos de pandemia}

Carlos Colombo

carloshcolombo@gmail.com

Si hablamos de la cobertura que realizan los medios de comunicación de la pandemia de Covid 19, que viene atravesando en mundo en general y con un pico de la primera ola en Argentina, debemos decir que la misma es amplia y generosa, desde su inicio hasta este mes de septiembre en que nos encontramos debatiendo el tema en "Pensar la comunicación 2020. Investigadores, docentes y comunicadores".

Dicha cobertura mediática, amplia generosa, lógicamente abarca absolutamente los distintos tópicos de la enfermedad.

Tal vez lo más importante esté dado en cuanto a la información diaria sobre contagios y fallecimientos, de la misma manera que se ofrecen las estadísticas sobre aquellas personas que han logrado ya salir de la infección y están volviendo a sus tareas y a su vida normal.

La situación hoy en la provincia de Santa Fe, a día 4 de septiembre, es sumamente complicada, puesto que estamos con un pico de la primera ola de casi unos 800 casos diarios en todo el territorio provincial y hemos llegado a más de 400 contagios en la ciudad de Rosario.

Esto ha llevado a que justamente en el día de hoy el gobernador, Omar Perotti, en una reunión que está manteniendo con el ministro de Salud de la Nación, Ginés González García, estén analizando diferentes medidas para volver hacia atrás en algunos puntos respecto de las aperturas y permisos que se habían ido dando sobre el Aislamiento Social Preventivo y Obligatorio (Aspo) de la cuarentena.

En ese sentido, se esperan para esta tarde o noche anuncios revirtiendo algunas de esas aperturas, pero lamentablemente ya hay sectores, como es el caso de los gastronómicos, que están cortando calles enojados porque van a volver hacia atrás. 
Seguramente lo primero que se van a cerrar son bares y restaurantes, lugares de reuniones, se va a reducir la movilidad de peatones y vehículos y, lamentablemente digo, no se comprende por parte de estos sectores comerciales (que sin duda se ven perjudicados, más allá de las ayudas económicas que se puedan otorgar desde los gobierno nacional, provincial y municipal) que de esta situación compleja, difícil terrible que atravesamos por la pandemia, de la única forma de podremos salir es trabajando en conjunto autoridades y ciudadanos, y si hay que dar un paso atrás para evitar mayor contagiosidad y muertes, hay que darlo sin dudar.

En cuanto a los medios de comunicación, el despliegue informativo es muy amplio, tanto en la prensa escrita como radial y televisiva.

Pero debemos marcar claramente que, lejos quedaron aquellos días iniciales de la pandemia donde absolutamente todos los medios estaban juntos, incluyendo aquella tapa de todos los diarios nacionales, el 19 de marzo de este año, titulando: "Somos responsables".

Fue la primera vez en la historia de la prensa gráfica argentina que todos los diarios se pusieron de acuerdo para salir con una misma portada y trabajar conjuntamente, con el gobierno y autoridades sanitarias, informando y convocando al pueblo a compenetrarse y comprometerse con la necesidad de mantener el aislamiento, el distanciamiento, el uso del barbijo, de quedarse en su casa y salir solo a negocios de cercanías para cuestiones necesarias.

Decía, lejos estamos de aquellos días, hoy ya de alguna u otra manera comienzan aparecer las notas, las opiniones y los editoriales de periodistas y comunicadores, acompañando la línea editorial de los principales medios nacionales, opuestos al gobierno del presidente Alberto Fernández, hablando de la cuarentena como "infectadura" o la "cuareterna".

Estas críticas periodísticas a la cuarentena o a la supuesta falta de libertad, toman carnadura en algunos sectores minoritarios de la sociedad que salen a cacerolerar o marchar contra las medidas que toma el gobierno para encauzar una pandemia que enferma, llena las camas de las unidades de terapia intensiva y, lamentablemente, se cobra miles de vidas sin preguntar por la ideología o el sector social al que pertenece. Aunque como siempre, los 
sectores más pobres y pauperizados lo sufren mucho más, ya que viven hacinados y no cuentan con las condiciones mínimas de una vida digna.

Estos planteos de algunos sectores de la sociedad, aupados en la oposición política y difundidos ampliamente por los medios concentrados de comunicación desde Capital Federal hacia el resto de país, señalando que a los ciudadanos le roban la libertad para salir a la calle, impidiendo que todo el mundo pueda moverse o sosteniendo que el gobierno encierra a las personas en sus casas, toman peso en distintas capas sociales que repiten ese discurso, cuando la realidad es que lo único que se intenta con el Aspo y las medidas restrictivas, respecto de horarios o cierres comerciales y movilidad de personas, es evitar más contagios y fundamentalmente más fallecimientos.

En cuanto al canal de la provincia, Radio y Televisión Santafesina, siempre se ha tenido la prudencia de informar correctamente, consultando constantemente a las fuentes, esto es Ministerio de Salud de la provincia y Secretarías de Salud Municipales, fundamentalmente de las ciudades de Rosario y Santa Fe, pero también a cada municipio o comuna cada vez que había que cubrir periodísticamente un brote de contagio u otra información relacionada con la pandemia.

Insisto que en este momento la situación que atraviesa la provincia de Santa $\mathrm{Fe}$, en cuando al número de contagios de Covid 19, es altamente compleja con una ocupación de camas de terapia intensiva superior al 60 por ciento de toda la provincia, con picos en algunas localidades del 80 por ciento,

Es por estos datos complejos, que es sumamente interesante esta idea de Pensar la comunicación y analizar concienzudamente qué y cómo abordan el tema los medios.

Son los medios quienes van a marcar agenda y formar la opinión ciudadana.

Es la radio, el diario y la televisión, a través de sus periodistas y comunicadores, los que le marcan a los ciudadanos y a las ciudadanas algunas pautas de cómo encarar y manejarse esta pandemia, que nadie había vivido antes. 
Es por ello que, si tensamos la cuerda hablando "cuareterna", "infectadura" o una periodista como Viviana Canosa toma al aire de una botella que dice tiene dióxido de cloro, atentando contra la salud pública de la población, queda claro que a esos medios poco les importan las personas y solo están enfrascados en una pelea contra el gobierno nacional.

Por eso, en épocas como estas, siempre es bueno volver a aquellos pensadores, como Arturo Jauretche que nos decía que "venía a consolidar esa saludable desconfianza popular a la letra impresa y a la voz de la radio, que salva a nuestro pueblo en las grandes circunstancias históricas".

Carlos Colombo, Licenciado en Comunicación Social, docente de la Cátedra de Producción Radiofónica de la Escuela de Comunicación Social de la Facultad de Ciencia Política la Universidad Nacional de Rosario. Integró el Directorio de Radio y Televisión Santafesina Sociedad del Estado de 2015 a 2020. Fue 12 años secretario de Comunicación y Medios de la UNR. Trabajó como periodista en LT8 Radio Rosario, Diario La Capital y Canal 5, entre otros medios. 
Santa Cruz en la pandemia: Solidaridad a flor de piel

Alfredo Fernández

Docente Investigador UNPA UARG afernandez@uarg.unpa.edu.ar

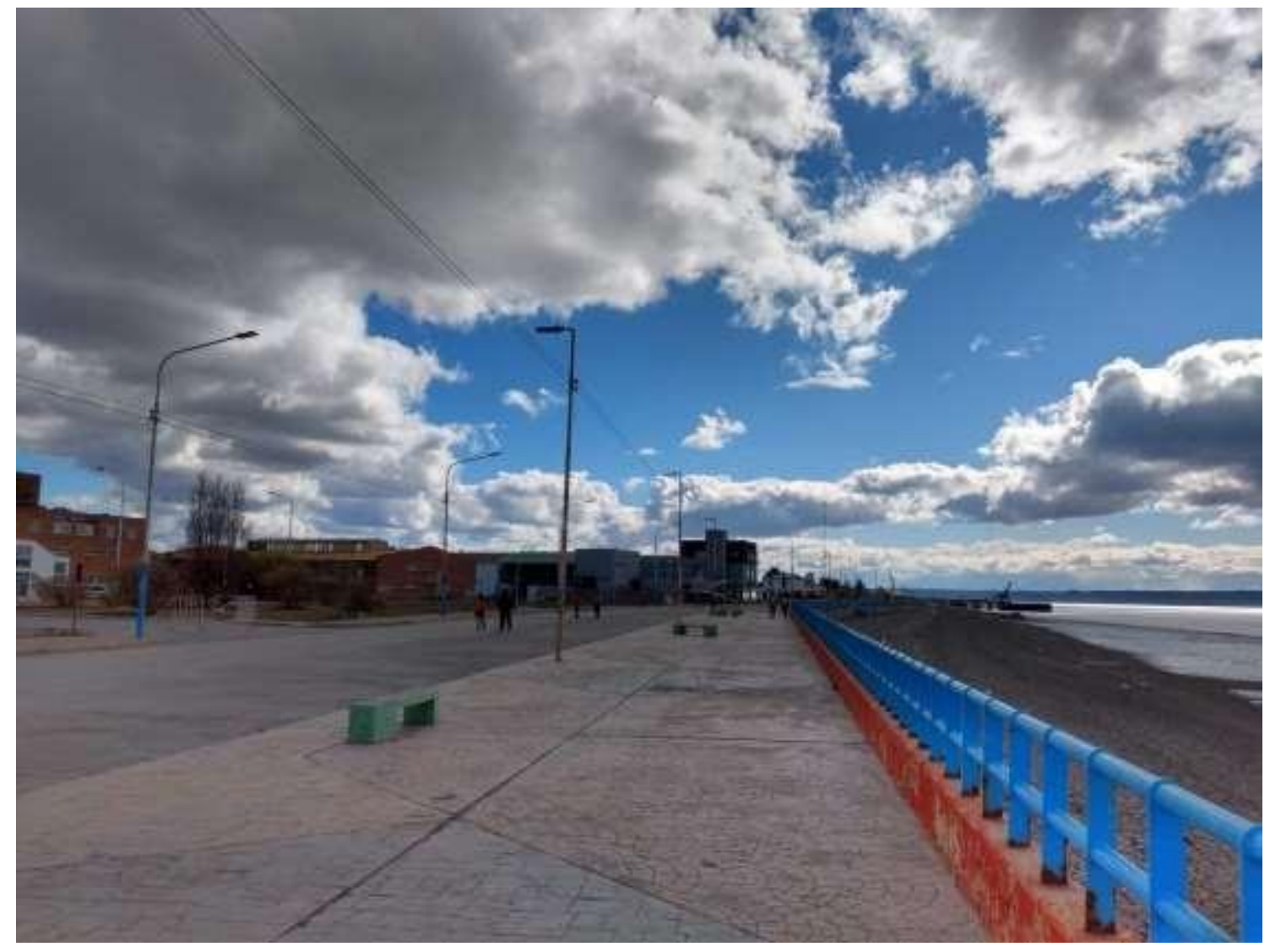

Una de las tantas tardes de aislamiento en la costanera local 
Santa Cruz vivió, como todas las provincias del país, la situación particular del aislamiento como medida preventiva. Los primeros casos de Covid 19 se dieron en turistas en El Calafate. Luego el virus llegó a cada rincón de la provincia.

Ni bien se conoció el decreto del aislamiento el 19 de marzo de 2020, comenzaron las acciones solidarias. Por ejemplo, la Unidad Académica Río Gallegos de la UNPA (Universidad Nacional de la Patagonia Austral) convocó a los pocos días a un Banco de Voluntariado, a fin de relevar posibles aportes a la comunidad universitaria para la atención de tareas derivadas de la emergencia sanitaria por la pandemia del coronavirus COVID-19. Los voluntarios acompañaron en una colaboración directa con las áreas del Estado Nacional, Provincial o Municipal en tareas de atención primaria en salud, acompañamiento o intervenciones en familia en riesgo, u otras que sean demandadas para la atención de la situación de emergencia sanitaria. En el primer día de convocatoria se inscribieron casi 300 voluntarios, entre personal docente, no docente y alumnos de distintas carreras.

Otra de las acciones emprendidas fue la confección de elementos de protección para el personal de salud. Cada kit estaba comprendido por botas, camisolín, barbijo y cofia. La tarea se realizó bajo la supervisión de la Comisión de Seguimiento integrada por docentes de la Escuela de Enfermería y profesionales del área de Higiene y Seguridad de la UARG.

Del plantel de voluntarios se convocó a más de 30 para armar moldes con los modelos aportados por el Hospital Regional de Río Gallegos y se distribuyeron junto a los materiales necesarios, telas, elástico, cinta e hilo. Así cada voluntario, desde su casa y en la medida en que la UARG fue teniendo acceso a los materiales, comenzaron a preparar los kits que incluyen botas, camisolín, barbijo y cofia.

La solidaridad también se manifestó a través de la campaña de recolección para estudiantes que no tienen PC. A tal fin se invitó a la comunidad universitaria a colaborar con la donación de tablets, notebooks, netbooks o PCs para ser acondicionadas y entregadas a alumnos de la Universidad que no cuentan con recursos informáticos. De esta manera se 
buscó facilitar la continuidad en los estudios de los alumnos, que actualmente se realizan de forma no presencial.

Como la Universidad, otras entidades se abocaron también a brindar acompañamiento y desarrollar determinadas acciones solidarias, como proveer diariamente a barrios carecientes de raciones de alimentos y elementos de higiene para que puedan ser distribuidos entre las familias. Desde el principio, la solidaridad de todos los actores estuvo presente. Y continúa hoy. 


\section{Pensar la comunicación-educación en tiempos de A.S.P.O.}

Alejandra María Gordillo agordillocorominas@gmail.com

La experiencia de llevar adelante prácticas de comunicación-educación mediadas completamente por la virtualidad no es novedoso para quienes ejercen la docencia o eligen esa modalidad para hacer sus trayectos de formación. El aula dejó de ser el espacio de encuentro con el otro a través de la mirada, las conductas, la gestualidad para convertirse en un entorno mediado por Tecnologías de la Información y la Comunicación, exigiéndonos una auténtica adaptación. Los casi dos años de Aislamiento Social Preventivo Obligatorio (ASPO) motivado por la pandemia de COVID 19 nos impusieron desplegar prácticas novedosas y amigarnos con otras estrategias de comunicación pedagógica. Esta realidad nos enfrentó al desafío de adecuar la transmisión, producción y gestión del conocimiento en un contexto de cambios que ha dejado de ser instrumental para ser estructural. Las mediaciones tecnológicas que ya estaban presentes en diversos ámbitos de nuestra vida cotidiana dejaron de ser una opción para ser imprescindibles, porque nos permitieron mantener los vínculos afectivos, sociales, productivos y por supuesto, educativos. Aprendimos a tender puentes que mediaran aún más el proceso de enseñanza-aprendizaje en el que, como sabemos, la comunicación juega un rol imprescindible de vínculo, relación y comunión dialógica, de construcción conjunta de sentidos y construcción conjunta de nuevos conocimientos donde los saberes se ponen en juego, se debaten y nos enriquecen. Asumiendo la importancia de vincularnos haciendo uso de tecnologías que nos permitieran encontrarnos en la virtualidad y nos permitieran ampliar nuestros horizontes de actuación en el rol de educadores no presenciales o virtuales. Rompimos las fronteras temporo-espaciales a las que estábamos acostumbrados, asumiendo aquello que Begoña Gros (2015) denomina como la caída de los muros del conocimiento en la sociedad digital y la consiguiente aparición de pedagogías emergentes que se caracterizan por promover aprendizajes "sin costuras", en los que la ubicuidad y los entornos personales de 
aprendizaje son pilares fundamentales de esos nuevos espacios atravesados por la virtualidad. Ante la imposibilidad del encuentro presencial intervenimos y aprovechamos las múltiples oportunidades de incentivar otros encuentros, otros puentes, otras mediaciones y entonces nos enriquecimos con más escrituras - ¿acaso no estamos siempre escribiendo con frecuencia en las redes, en los posteos, en las devoluciones, en los textos que escribimos para contribuir y orientar la interpretación de los textos que subimos a las aulas virtuales? - pero también con el uso de otros recursos comunicacionales como un video o un audio, una clase grabada, un hipertexto que se enriquece con vínculos que sugieren otras lecturas, otras miradas e interpretaciones. Expandimos la experiencia y motivamos el acceso al conocimiento más allá de los textos. Rompimos la horizontalidad de los procesos lineales de comunicación docenteestudiantes; estudiante-docente, estudiante-estudiante y nos sumergimos en prácticas pedagógicas situadas y diversas que nos permitieran conectar de manera interactiva con los estudiantes.

Alejandra María Gordillo - Profesora Asociada Ordinaria - investigadora de la Universidad Nacional de Chilecito. Lic. en Com. Social, Esp. en Docencia Universitaria, Magister en Ciencias. Sociales y Humanidades. 
Hibridaciones pospandémicas: Nuevos escenarios comunicativos

Fernando Irigaray

fgirigaray@gmail.com

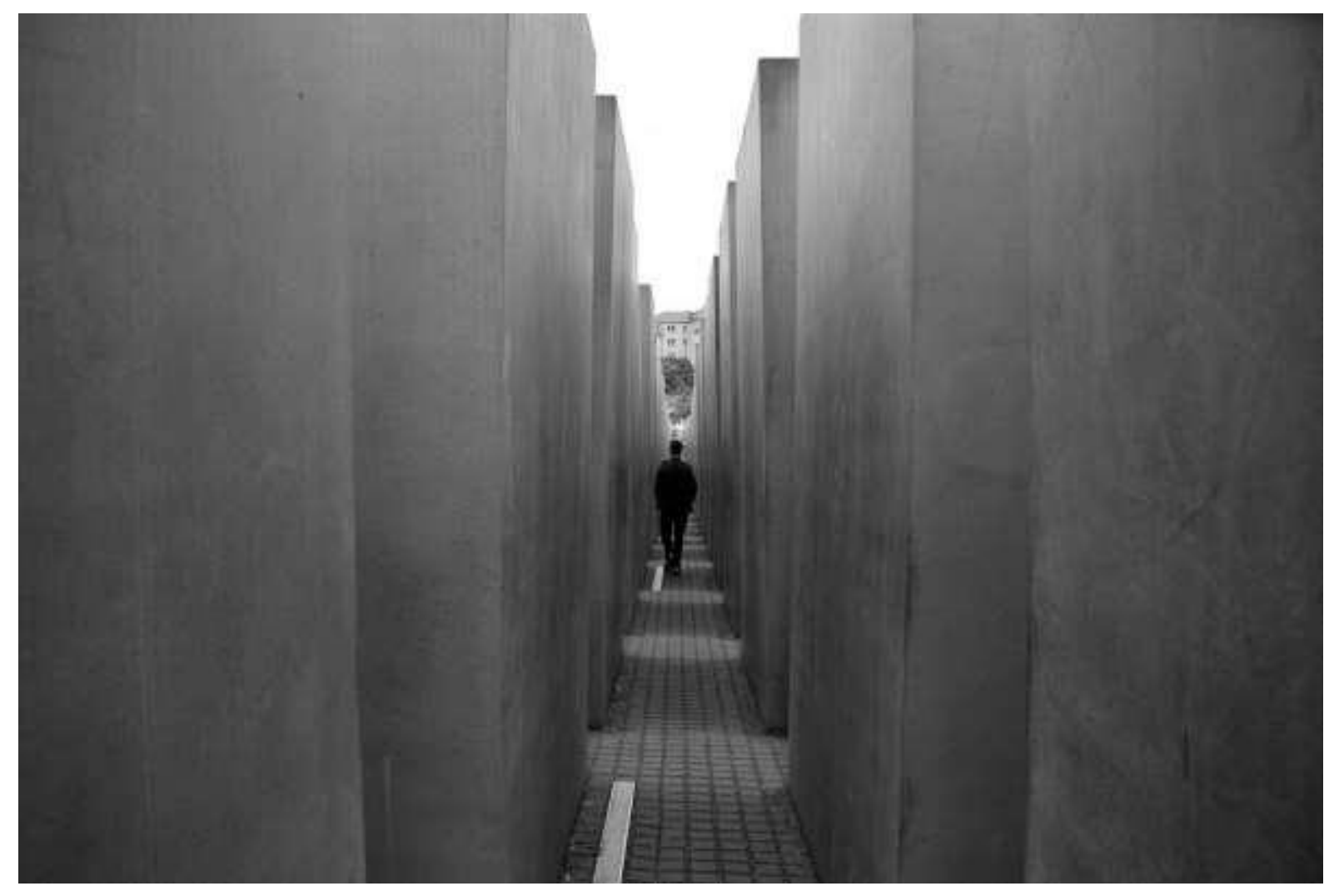

Fotografía: emoro

(https://pixabay.com/es/photos/monumento-berl\%c3\%adn-s\%c3\%admbolo-ciudad-2549150/ ) 
A más de un año de mis obtusas y apuradas reflexiones que intentara en Escenarios pospandémicos de la Comunicación, me reencuentro con algunas ideas que en este transcurrir temporal, percibo lamentablemente que no tan solo no han cambiado el rumbo sino que se han profundizado, acrecentando mi posición pesimista sobre la sociedad y la etapa histórica en la que nos a tocado vivir.

Cientistas sociales, filósofos y demás pensadores a comienzos de la pandemia llenaron páginas de ingenuo optimismo postulando que la única forma de salir de esta crisis global, era a partir de la unión, el bien común y la solidaridad, pero no tan solo no hubo un cambio en ese inexorable derrotero, sino que se ahondó en lo que tanto se temía, la desigualdad, el egoísmo, la avaricia, la nula importancia de la otredad.

En aquel video que hago referencia marcaba una etapa de presente continuos, de futuros difusos, de dominios de la obviedad, de la retórica del exceso exacerbado, de la operación política recursiva y la hiperficcionalidad permanente en los universos narrativos de los discursos periodísticos, pero no estaba siquiera en la imaginación de la mente más retorcida que los medios del establishment y una inmensa cantidad de periodistas de esos espacios, pasarían de militantes del campo opositor a la profunda militancia anticuarentena y antivacuna.

También vimos en este año como se potenció la clausura, ya no como lo plantéabamos el año pasado, del debate de ideas, sino directamente como exclusión del otro.

En cuanto a las producciones, pudimos observar cómo se fueron consolidaron las narrativas híbridas, donde los bordes de delimitación de las distintas esferas se hicieron cada vez más difusas acentuando el mestizaje no tan solo en sus posibilidades técnicas sino en lo estético y en la dimensión de la producción de los productos comunicacionales, incorporando el sistema de videoconferencia de formato home a la estructura televisiva broadcasting.

Cuando por años se proclamaba la muerte de la TV en vivo, irrumpió con fuerza el streaming desde nuevas plataformas, que salió de la esfera de nicho de los gamers a disputar el sentido en la transmisión de eventos deportivos, con insólitas peleas de periodistas queriendo negar la legitimidad de altas audiencias participativas de estos nuevos 
comunicadores de las redes en directo, desnudando lo patético del supuesto periodismo especializado en deportes, que no puede salir de la opinión obtusa, malintencionada, ciega y sin ningún tipo de fundamento sostenido, al criticar a las figuras deportivas por no darle entrevistas a ellos, negándoles el derecho a la propia palabra.

El directo explotó pero mudó su locación del estudio de TV con conexión con los hogares de los entrevistados o directamente cambió el escenario del plató a la casa de estas nuevas estrellas del sistema mediático. Podemos decir que cambió el domicilio de la emisión, del broadcasting al homecasting.

Pero también vimos la punta del iceberg de la disputa del negocio de estas transmisiones deportivas, con la compra de la empresa del jugador del Barcelona Gerard Piqué de los derechos de la liga francesa para España y trabajar con Ibai Llanos en la transmisión por Twich con los partidos de PSG y Lio Messi.

La recuperación paulatina del espacio y el territorio después de las ASPO y la DISPO, va a influir en el resurgir de las narrativas de expansión territorial o narrativas espaciales que se se venían expandiendo, tanto en los ámbitos de no ficción, las artes performáticas, y en la inclusión en varias campañas políticas y sociales, que habían sido truncada su aparición y desarrollo.

Se trata de relatos que habitan en un posterritorio, a partir de la conexión que hibridan los flujos físicos y virtuales en un entramado físico-digital de límites indeterminados y geografías solapadas, a través de los dispositivos móviles.

Nos tocará habitar un tiempo de hibridaciones, de expansión de relatos, de multiplicidad de plataformas, de formatos extendidos y de contenidos extracortos, de narrativas efímeras, del directo y de bajo demanda, de infoxicación asfixiante y mentiras reveladas y fundamentalmente de una clausura del diálogo sinceroMg. Fernando Irigaray - Director de Comunicación Multimedial, de la Maestría en Comunicación Digital Interactiva y Director Ejecutivo de la Cátedra Latinoamericana Narrativas Transmedia en la Universidad Nacional de Rosario (UNR) 


\section{Democracia, neoliberalismo y pandemia}

Gabriel Lamanna

liclamanna@gmail.com

Varios hechos han venido sucediendo desde de la extinción de la Unión de Repúblicas Socialistas Soviéticas. Los más preocupantes son la supervivencia del Capitalismo como único orden o sistema económico y social (hecho que popularizó Francis Fukuyama en 1992, pero inicialmente anticipó el sociólogo Daniel Bell en 1960); la obsesión de los dirigentes políticos por conseguir, construir y conservar el poder; el debilitamiento de las democracias sociales; el fortalecimiento de las democracias neoliberales; el resurgimiento de los sectores de extrema derecha; el autoritarismo de los partidos gobernantes; la concentración de los medios masivos de información en pocos grupos económicos; la convergencia de poder omnímoda entre las elites políticas y económicas; y el vertiginoso proceso de desarrollo de las nuevas tecnologías (donde se destacan las de la información).

Con el transcurso de los años la preocupación por el futuro de los sistemas democráticos de gobierno ha ido in crescendo. En el siglo IV a.C, Aristóteles advirtió en su obra "Política": "(...) el que es verdaderamente popular ha de considerar de qué modo podrá evitarse que la gente común no esté muy necesitada, porque el estarlo es causa de que sea malo aquel gobierno popular". $Y$ hace casi dos siglos, cuando Alexis de Tocqueville escribió "La democracia en América", remarcó: "Los funcionarios públicos, en los Estados Unidos, permanecen confundidos en medio de la multitud de los ciudadanos; no tienen ni palacio, ni guardias, ni trajes de ceremonia. Esa sencillez de los gobernantes no se debe solamente a una característica del espíritu americano, sino a los principios fundamentales de la sociedad".

Sin embargo, poco parece haber cambiado, a punto tal que los más destacados investigadores y politólogos estadounidenses vienen advirtiendo sobre los riesgos actuales. $Y$ 
quizás la expresión más contundente haya sido expuesta en el ensayo de Steven Levitsky y Daniel Ziblatt: "Cómo mueren las democracias", publicado en el año 2018.

Pero la alarma ha alcanzado un punto tal vez insospechado durante el 2020, cuando el mismísimo Richard Haass -presidente del Council on Foreing Relations- publicó un artículo en el número de mayo/junio 2020 de la Revista Foreign Affairs con un título inquietante: "La pandemia acelerará la historia en lugar de remodelarla". Allí queda plasmado el riesgo que corren las democracias en el período post Covid-19.

Gabriel Lamanna Periodista y Licenciado en Comunicación Social. Universidad Nacional de La Plata (UNLP). Miembro fundador del Centro de Estudiantes de Periodismo (el primer Centro estudiantil abierto -a pesar de estar prohibido- durante la última dictadura cívico/militar en Argentina). Profesor Titular e Investigador de la Facultad de Periodismo y Comunicación Social (FPyCS) de la UNLP desde hace más de tres décadas. Creador de las materias "Comunicación Alternativa" (Comunitaria o Popular) y de "Comunicación Mediática y Organizaciones" (FPyCS/UNLP). Dircom, Asesor y Consultor en Comunicación de diversas organizaciones nacionales e internacionales. 


\section{La infodemia solo es reversible con el ejercicio profesional del periodismo.}

Lila Luchessi

luchessi@gmail.com

Pensar la comunicación, la información y las noticias en contextos de incertidumbre plantea la necesidad de comprender los impactos emocionales de la información de catástrofe sobre las audiencias y el modo en que una pandemia estipula las necesidades globales, locales y hiperlocales de información.

En este contexto, la tarea del periodismo -o la gestión profesional de las noticias- es central. En situaciones de peligro o alarma social, la confusión, desinformación o lo que la Organización Mundial de la Salud categoriza como infodemia solo es reversible con el ejercicio profesional del periodismo.

Sin embargo, por la construcción que la mayoría de quienes desarrollan sus tareas en diferentes medios realizan respecto de la categoría de independencia, el uso de fuentes oficiales, relacionadas con organismos estatales nacionales y supranacionales, genera desconfianza, reticencia y en más de un caso reacción.

Esto genera que se incorporen versiones, posicionamientos y pseudonoticias que tienden a confundir, atemorizar y básicamente desinformar a la población. Estas situaciones, en escenarios de profunda incertidumbre, colaboran con la sensación de perplejidad, desamparo y angustia. También, profundizan la incredulidad de las audiencias sobre las instituciones en la medida en que se alejan de cualquier forma de certidumbre.

Este tipo de narrativas abonan la construcción de fuertes creencias, mayoritariamente binarias, sobre formas conspirativas para el ejercicio de la política. Acentúan posicionamientos antipolíticos e impactan directamente sobre la cantidad de personas expuestas a contagios por falta de cuidados o mera oposición a todo lo que resulte oficial.

\footnotetext{
IICom (Instituto de Investigaciones en Comunicación) 
La lógica de la reacción, cuya única propuesta es oponerse a cualquier iniciativa que se toma desde las dirigencias públicas o privadas, tiene una fuerte raigambre antes del comienzo de la pandemia y se acentúa con la imposibilidad de proyectar certidumbre sobre la salud, la prevención y la gestión de la salud, al tiempo que se dicotomiza su prioridad en competencia con la economía.

Contrariamente a la necesidad de los datos chequeados, sostenidos en estadísticas y explicados por voces autorizadas, como propondría el periodismo de precisión, desde la gestión de la información se relativiza la capacidad de gestión de los organismos estatales y la experticia de quienes trabajan como asesores científicos del gobierno.

Esto lleva a construir una narrativa paradojal y altamente inconsistente. Para degradar las voces oficiales y la autoridad que se genera desde los centros de investigación y conocimiento, se construyen historias ancladas en la emoción y en las que se omiten datos -o en el peor de los casos se los tergiversan- para instalar versiones, tensiones y pseudo acontecimientos que dan entidad a la creencia colectiva en la conspiración.

Este panorama insta a repensar las relaciones entre la prensa y los organismos públicos. Cómo puede realizarse una gestión armónica de la tensión para rescatar insumos interesantes para construir una información social que cubra las necesidades informacionales de la población.

En este punto, una de las cosas más relevantes que deja la pandemia es la gestión de un acontecimiento -que es global- y unas necesidades de información finamente localizadas. Es que las ciudadanías requieren datos específicos acorde con la cantidad de casos, las cepas en circulación, las políticas concretas en cada Estado (nacional, provincial o municipal) en un contexto de tensiones entre quienes administran la crisis y quienes deben narrarla.

Entonces, volver a los parámetros que se estipulan en el proceso de newsmaking para garantizar el correcto tratamiento de los datos, puede ser el aporte central e indispensable de los periodistas para evitar la infodemia y la naturalización de las operaciones sostenidas en fake news. 


\section{Estar juntos en pandemia (¿y después?)}

Susana Martins

smartins1074@gmail.com

La pandemia dejó al desnudo problemas de profunda desigualdad en el acceso y el uso de la tecnología. Al mismo tiempo, nos obligó a revisar aquello que hay de sustancial en la práctica pedagógica y abrió nuevos desafíos para la educación superior en Argentina.

\section{En el inicio}

4 de marzo de 2020. Se confirma la llegada del primer caso positivo de coronavirus a nuestro país.

20 de marzo de 2020. Se decreta, por 15 días que luego se convirtieron en meses, el aislamiento social preventivo y obligatorio (ASPO) para todos los habitantes del país.

25 de marzo de 2020. Se da inicio al primer cuatrimestre de materias obligatorias de la UNLP según calendario académico.

Así arrancamos. Con lo puesto. En una cruzada épica que combinó lo que sabíamos con lo que podíamos; lo que teníamos con la fuerza de la voluntad y la creatividad. Esa que se activa con la adrenalina que nos da la conciencia de la emergencia.

Pero ¿qué sabíamos en el inicio? Probablemente, que las instituciones contaban con estructura, desarrollo y capital humano que pusieron a disposición. Y que donde no lo hubiere, se inventaría porque "primero los y las estudiantes"; que a nuestro compromiso ético debíamos sumarle profesionalismo para sostener el vínculo pedagógico.

Un vínculo que se puede definir como un contrato que se establece entre el docente y el estudiante, mediado a partir de un conocimiento específico, pero que pone en el centro de la 
escena la dimensión humana de la relación. El proyecto cultural de la Modernidad bregó por la racionalización extrema de ese vínculo: sobran ejemplos sobre conductas autoritarias en las instituciones educativas que se veían a sí mismas como garantes de la disciplina de los cuerpos. Sin embargo, la revisión post 70 de la pedagogía volvió a poner el foco en dos sentidos centrales de todo proyecto formativo: la escucha y el afecto.

Pues por ahí, entonces, debíamos ir con nuestros estudiantes enclaustrados, angustiados, temerosos. Porque era lo único que nos iba a permitir, la escucha y el afecto, sortear con prestancia y dignidad una situación desconocida para todos y todas. La formación de los sujetos, que excede por mucho a la enseñanza de contenidos o a la situación áulica específica, prevé una distancia pedagógica, pero al mismo tiempo una cercanía humana imposible de dejar por fuera del vínculo. Y allí reside el potencial del desarrollo de su plenitud, sea ese estar con presencial o virtualizado a través de una pantalla.

Por ello nos atrevemos a dudar de las afirmaciones que sentencian que se han borrado los cuerpos o que necesitamos volver a ámbitos de co-presencia para volver a estar juntos: en primer lugar, porque la presencialidad no garantiza cercanía afectiva y, en segundo lugar y, sobre todo, el estar juntos no se construye sobre una sola variable, en este caso, la copresencia, sino que es el resultado de un proceso vincular que se inicia en la clase, pero no muere en ella: perdura en el tiempo, atraviesa los espacios.

Quizás frente a la virtualización forzada haya que volver sobre la pregunta de lo que implica estar juntos, en este ámbito y en otros, por qué no.

Resulta importante recuperar estos saberes iniciales porque, un año y medio después, pueden perderse en la ciénaga de la velocidad cotidiana y entonces, olvidar de donde partimos.

Por lo tanto, perder de vista hasta donde llegamos.

Y lo que es mejor, qué descubrimos en el camino.

\section{En el camino}


Muchas fueron las dudas y dificultades que surgieron en el camino ¿Cómo contactarnos mejor con les estudiantes? ¿Qué tipo de actividades proponer para sostener el entusiasmo de semana a semana? ¿Qué potencialidades ofrecía el lenguaje digital para crear materiales, pero también para administrar y controlar las aulas virtuales? Cuando no había en disponibilidad un entorno propio ¿qué plataformas podían resultar más accesibles, cómodas, sencillas y disponibles?

Podemos, incluso, ordenar las preguntas y desafíos por niveles. A nivel de la infraestructura lo ideal sin duda fueron los entornos digitales propios por varios motivos:

- Están creados en plataformas accesibles a todos y todas.

- Están diseñados especialmente para convertirse en aulas virtuales.

- Dependen de servidores de las distintas universidades, por lo tanto, allí los datos y contenidos están resguardados.

- No consumen datos de los planes de internet de cada usuario, producto de un convenio entre universidades nacionales y el Ente Nacional Regulador de telecomunicaciones (ENACOM)

Este tipo de infraestructura, que no se dio en todas las Universidades Publicas implica también desarrollo, capacitación y capital humano. Y allí la pregunta es ¿cómo se organizaron dentro de la estructura administrativa de cada unidad académica los equipos de lo que se conoce como educación a distancia? ¿Con qué experiencia contaban? ¿Qué herramientas y capacitación necesitaron? ¿Qué tipo de apoyo material y humano recibieron por parte de las autoridades? Todas estas dimensiones se tornan válidas de cara a los procesos que vienen. Con pandemia o sin ella, los equipos deberán formar parte de los planteles estables de las distintas facultades, y bienvenido será que en épocas de "normalidad" se aboquen a capacitar a docentes y estudiantes sobre algunas cuestiones acerca de la relación tecnología-educación que excede lo meramente instrumental.

En ese sentido, otra zona de debate que se abre fruto de la experiencia del último año y medio es justamente aquella que interpela sobre qué nociones tiene la educación superior a la hora de hablar de (pensar y planificar) tecnologías. Lamentablemente, la idea de que las técnicas son meramente instrumentales y, por lo mismo, neutrales, es una idea que ha calado 
hondo en el sentido común de muchas de nuestras instituciones. Por ello, resulta clave abrir el debate sobre la dimensión política y subjetiva de las tecnologías y su relación con el campo de la educación.

Por cierto, se trata de un campo poco explorado que, en virtud de la pandemia, nos obligó a tomar decisiones más centradas en la intuición y en la creatividad que en desarrollos conceptuales sólidos. Sin duda abrir y sostener ese debate es un desafío formativo que debemos asumir más temprano que tarde.

Siguiendo con la propuesta de los niveles de análisis cabe preguntarse también por el nivel de lo normativo. ¿Cuál es el marco jurídico que habilita estas prácticas? Obviamente la situación sanitaria obligó a permanecer en un estado de excepción, pero como bien lo explica el término, la excepción no puede sostenerse en el tiempo. Y la vuelta a las aulas tal como la conocimos es probable que no suceda en un escenario a corto plazo. Por ello, la educación superior ya no puede pensarse en situación de "permanente emergencia" sino que debe problematizar algunos núcleos centrales:

- La cuestión normativa

- La igualdad y libertad de acceso

- Cuestiones de Titulación

- El problema de la evaluación y la acreditación de carreras, por citar algunos.

El tercer nivel que interesa manifestar es el de los usos y consumos de los jóvenes respecto a la tecnología. En una conversación con colegas surgían algunos imaginarios que rápidamente fueron cuestionados por datos de la realidad. A saber:

- Que los estudiantes manejan con solvencia las herramientas tecnológicas y que están familiarizados con la cultura digital.

- Que todos y todas tienen al menos un celular inteligente con el cual pueden acceder a los contenidos on line.

- Que la digitalización de los contenidos suponía una inmediata aceptación y provecho de tal situación

- Que lo más traumático de la experiencia pandémica iba a ser no poder acudir presencialmente a las aulas. 
Relatos e imaginarios que atravesaron sin duda las mentes de los docentes al principio de la pandemia y que, de una manera u otra, influyeron en su modo de adaptar, asumir o construir lo virtual. Lo cierto es que en el camino descubrimos que los estudiantes son, mucho de ellos, gamers, es decir, están familiarizados con el lenguaje de los videojuegos, pero no necesariamente saben como funciona un drive. O peor, no tienen experiencia de trabajo colaborativo en red. En el camino descubrimos que la brecha digital en muchos casos era más un tema de hard que de soft: es decir, que no había computadoras en las casas. Y que muchas veces el celular debía ser compartido entre varios, por no mencionar la naturaleza de las actividades solicitadas con lógica escolar (ensayos, escritos, mapas conceptuales) que les estudiantes debía realizar con la pantalla y el teclado de un Smart. De nuevo, el imaginario escolar no asume aún como natural el lenguaje audiovisual y permanece entroncado en una lógica escritural (por la jerarquía, la argumentación y la organización de ideas).

Finalmente, la virtualidad (excepción pandémica dixit), pasado el primer cimbronazo, abrió un universo de posibilidades para aquellos y aquellas que estaban más lejos, que tenían dos o más horas de viaje, que trabajaban en horarios complicados, que habían abandonado carreras completas o que por fin se decidieron a iniciar una. ¿Qué va a pasar con esos ciudadanos una vez atravesada la "excepcionalidad"? Las universidades públicas deberían ir pensando una estrategia de contención porque la situación social es muy compleja y excede el abro/no abro la presencialidad.

Por último y ya en un cuarto nivel de un orden absolutamente arbitrario, no quisiera dejar de mencionar el enorme debate que nos debemos como sociedad respecto a lo que se conoce como soberanía digital, algo que se puso de manifiesto en el contexto pandémico pero que habla de la inocencia ( $\mathrm{y}$ a veces la ignorancia) con la que nos manejamos en el mundo digital. Sin conocer el modelo de negocio que sitúa en el centro de la cuestión al extractivismo de datos y que contempla el diseño visual de las plataformas para que nos mantengamos más tiempo en ellas, sumado a la concentración de las corporaciones que manejan la digitalización del mundo, estamos muy lejos de poder tomar decisiones soberanas e inteligentes a la hora de usar las tecnologías de la comunicación para prácticas educativas. 
Al respecto solo una mención a una nota que escribió Esteban Magnani y que se llama "Educación virtual: no todo da lo mismo". Allí, este especialista en tecnología y sociedad advierte:

“¿Cuáles son las alternativas en un momento en que la pandemia apura los tiempos? En primer lugar, tener en cuenta el daño potencial de entregar los datos de los estudiantes a corporaciones extranjeras. En segundo lugar, tomar decisiones que permitan avanzar en el desarrollo de respuestas abiertas y libres en los que la tecnología esté al servicio de la pedagogía y no al revés. Esto se logra sobre todo con software libre que permite a los docentes hacer propuestas, pedir cambios que los programadores pueden realizar y que no dependen del deseo de una empresa privada que realizó su plataforma de acuerdo a criterios generales que, posiblemente, tienen poco que ver con las realidades locales. El software libre permite también el alojamiento en servidores propios que dan garantías acerca de la privacidad de los datos. Por otro lado, estas tareas pueden ser provistas por trabajadores locales que de esta manera consiguen empleo y refuerzan la red de conocimientos necesarios para continuar el proceso"(1)

\section{En el después}

Difícil aseverar mientras se escriben estas líneas que haya un después. Hace poco, el conocido biólogo molecular Ernesto Reznik dijo "no tengo dudas de que habrá más vacunas, tampoco de que el coronavirus seguirá existiendo". Somos testigos de una pandemia global como no se vivía hace más de 100 años. Eso, de suyo, abre un horizonte de incertidumbre y de preguntas más que de respuestas. El después quizás es hoy, donde podemos preguntarnos qué nos pasó, cómo lo resolvimos, qué ganamos, qué aprendimos. Pero sería muy poco estratégico de nuestra parte no sumar el cúmulo de reflexiones, barajar y dar de vuelta.

Se trata de una experiencia única que nos pone ante situaciones desconocidas y que nos obliga a mirar la realidad desde otra perspectiva. Usemos eso a nuestro favor, que es el favor de la humanidad, no de estos tristes contemporáneos que salimos al ruedo con lo puesto y regresamos lo más digno posible de la batalla.

Hagámoslo por los que no vivieron para contarla. A ellos y ellas, se lo debemos.

\footnotetext{
IICom (Instituto de Investigaciones en Comunicación)

Facultad de Periodismo y Comunicación Social

Universidad Nacional de La Plata
} 
Question/Cuestión, Vol. 3, N70

Diciembre 2021

ISSN 1669-6581

Lic. Susana Martins. Docente e Investigadora. FPyCS- UNLP

\section{Notas}

(1)La nota completa puede leerse en https://www.ei-ie.org/es/item/24960:educacionvirtual-no-todo-da-lo-mismo 


\section{El periodismo de investigación durante la pandemia}

Miguel Mendoza Padilla mendopadilla@gmail.com

Pensar el periodismo de investigación antes y durante la pandemia no tiene casi diferencias, esta especialización dentro del periodismo está atravesando una crisis que hace muy difícil poder llevar adelante la tarea. La falta de acceso a fuentes documentales y la no concreción de poder pautar entrevistas a fuentes personales dificulta mucho poder comprobar las irregularidades surgidas del elegido.

Por otro lado, la proliferación de las Fakes News (noticias falsas), y las operaciones a los periodistas por parte de personajes que se acercan para desviar el tema de investigación o de contaminar el trabajo del periodista con mala información, como decimos en la jerga te ofrecen pescado podrido.

Si bien con la pandemia el trabajo clave del Periodismo de Investigación PDI (trabajo de campo) se vio limitado, ya que los periodistas debieron adaptar su trabajo a poder realizarlo desde su casa o la redacción, y esto llevo a que muchas entrevistas se tendrían que realizar utilizando alguna plataforma a distancia (Teams, Meets o Zoom), el mismo se siguió realizando pero hoy en día y más allá de la pandemia, el PDI es ayudado por las operaciones políticas o mediáticas, que facilitan información o que ayudan a inventar fuentes o información falsa.

Es notorio esto último que estaba mencionando ya que siguen apareciendo pruebas del modus operandi del falso Abogado Marcelo D’Alesio donde estuvo involucrado el Periodista Daniel Santoro, que utilizaba la información que le pasaba el falso periodista.

Hoy en día con pandemia o sin pandemia el periodismo de investigación que llevan adelante los periodistas de los grandes medios de comunicación tiene una clara intencionalidad editorial que se podría traducir en intencionalidad política. 
Sin embargo y más allá de esta utilización que se haciendo de esta especialización del periodismo hay otros medios y periodistas que siguen trabajando y produciendo informes de investigación con la finalidad de poder dar a conocer la "verdad" que se intenta mantener oculta.

Por otro lado, la enseñanza del PDI, también se ha ido adecuando a estos tiempos de pandemia, se realizan trabajos más de Periodismo de precisión o periodismo de datos (PDP), se utilizan datos que generan establecimientos públicos, investigaciones de carácter social y algunas fuentes especializadas que acceden a ser entrevistadas. En otros casos se realiza un mix, entre el PDI y el PDP, se busca un tema que pueda ser abordado de ambos tipos de periodismo y de esa manera no se fuerza el tema del des ocultamiento de algo, que muchas veces es difícil de poder probar. Desde esta perspectiva se han logrado trabajos muy interesantes vinculados a temas como la producción de Vacunas (2020), el Covid 19 y el dengue (2020), el aumento de hortalizas (2021), el cupo trans en la administración pública (2021), las Fake News en pandemia (2020/2021), etc; como se pude observar son temas interesantes y con cierta profundidad en materia periodística.

Miguel Mendoza Padilla, Docente en las Universidades Nacionales de La Plata, Avellaneda, La Matanza - Integrante del IICOM, Integrante de Institutos, Categoría II como investigador, evaluador de proyectos de investigación y de extensión en universidades nacionales. 


\section{Espacios, identidades y representaciones: El culto del Milagro en contexto de pandemia}

Daniela Nava Le Favi

danielanavalefavi@gmail.com

Esta reflexión es un aporte a la línea que se planteó en el video, es decir, presenta algunas actualizaciones para pensar cómo un culto religioso tiene ciertas continuidades y rupturas en los escenarios que nos plantea (y atraviesa) el COVID-19.

Todos los septiembres de cada año miles de personas - en su mayoría- del interior provincial, caminan días y noches para llegar a la Capital y participar de la procesión al Señor y la Virgen del Milagro en Salta- Argentina, una devoción que congrega también a eclesiásticos, políticos y miembros de la sociedad civil. El Milagro se remonta a 1692, año en el que ocurre un fuerte terremoto que destruye la ciudad y alrededores. Según su origen mítico, cuando las imágenes de los Santos Patronos salen por las calles de la ciudad, cesan los temblores.

La pandemia del COVID-19 implicó una explosión cultural (Lotman, 2002). En esta breve reflexión, se focalizará en ciertas continuidades y rupturas en términos espaciales e identitarios, que hablan -también- de diversas formas de exclusión-inclusión.

Dentro de las continuidades se podría nombrar el "sacrificio" de la práctica: si antes los peregrinos tenían que caminar días y noches para llegar a la procesión -un ritual que por sólo ese momento los "incluye" como parte de esa ciudadanía "salteña"-, en pandemia ese "sacrificio" se puede vislumbrar en la posibilidad de acceso a la conectividad en un interior provincial que tiene profundas desigualdades en este aspecto.

Durante septiembre de 2020, ciertos grupos de Facebook que se denominaron "Peregrinos Virtuales", "Peregrinos de San Antonio de los Cobres" empezaron a emerger y/o aumentar su capacidad de producción de contenidos. Allí, si bien se lee la permanencia de la representación de "peregrinos" hay un corrimiento espacial en términos de lo "virtual". Además, 
se sigue reforzando la localía, una identidad que antes estaba inscripta en estandartes, remeras y que ahora se lee en las nominaciones de esos grupos de la red social. Este proceso permite pensar, por un lado, que si en términos espaciales existió una ruptura, por el otro, hay una repetición y permanencia en el re-fuerzo de una identidad "local".

La representación de la "protección" también se lee en numerosos memes de los Santos Patronos persiguiendo una imagen del COVID-19; lo que originó una contra-respuesta en imágenes que retomaban a series como los Simpsons y al Arzobispo de Salta para anclar el culto sólo como protectores contra terremotos.

Este proceso de religiosidad, entonces, permite reflexionar sobre cómo se articulan las representaciones, las identidades, los espacios, las formas de exclusión e inclusión, las esperanzas y las ansiedades en contexto de pandemia, más acá, pero también, más allá del campo religioso. 


\title{
Comunicación y religiosidad
}

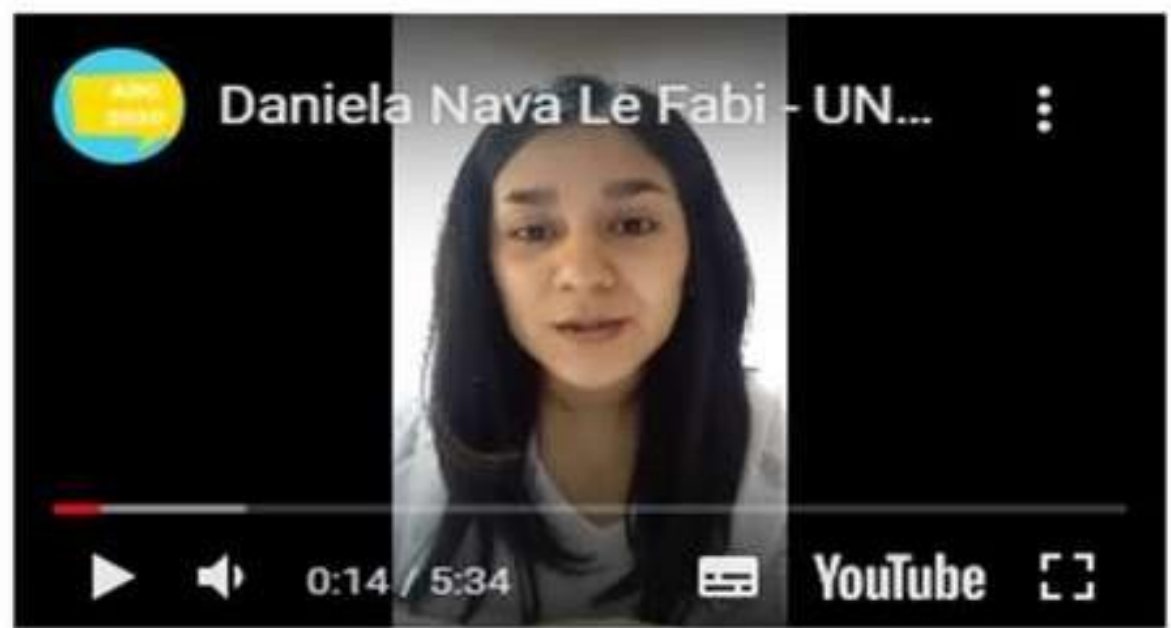

\author{
Autopercepción de la religiosidad en el NOA, \\ presencia en el espacio público, ligadas a los \\ terremotos (geocultura). Religiosidad y gobierno \\ provincial, los medios de comunicación e imágenes \\ religiosas, religiosidad y sociedad en el contexto \\ del Covid 19.
}

\section{Autores:}

\section{Daniela Nava Le Favi}

Daniela Nava Le Favi - Doctora en Comunicación por la UNLP. Becaria Posdoctoral del CONICET/IBIGEO/ UNSa. Miembro del INCOPOS (UNSa). Docente en FH de la UNSa. 


\section{Mediaciones en pandemia: Derecho a la Conectividad}

Paula Inés Porta

paulainesporta@gmail.com

https://orcid.org/0000-0002-1399-1400

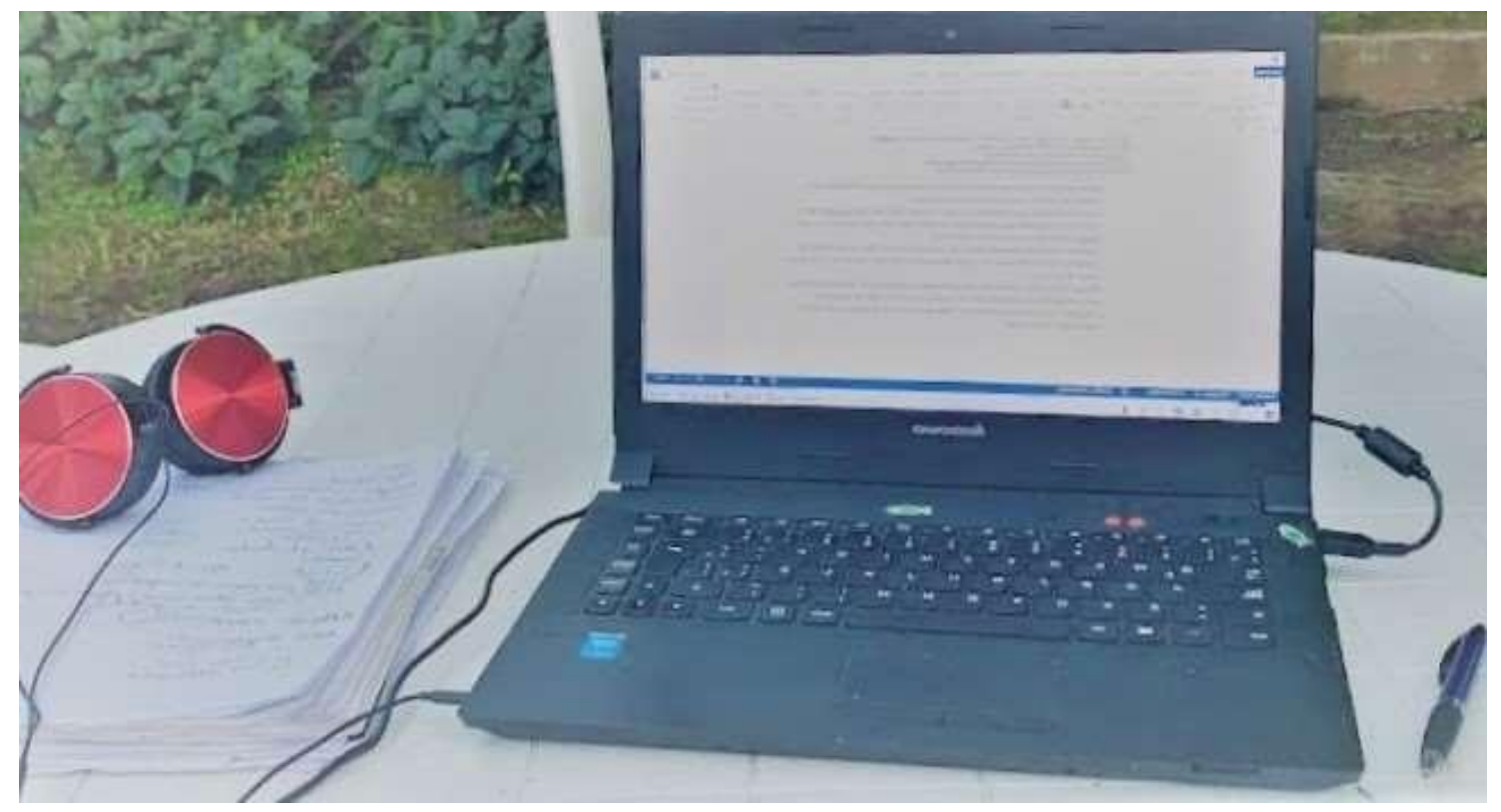

La pandemia atravesó nuestra cotidianeidad a partir de marzo del año 2020 nos aislamos ahí donde quedamos. Sorprendidos y con una gran incertidumbre en nuestra Argentina y en el mundo, la opción para preservar la vida fue aceptar el confinamiento. En ese contexto, la comunicación, la producción social de sentidos, adquiere una centralidad potenciada por la capacidad de la convergencia digital y la virtualidad. Quedamos atravesados por las tecnologías de comunicación digital, diversos dispositivos conectados a internet, 
extienden nuestros sentidos, nuestro conocimiento y nuestra memoria La comunicación se convirtió en oportunidad para continuar: trabajos, estudios, trámites, gestiones, encuentros y afectos se convirtieron en bit para así invadir fibras ópticas, satélites y cables. Mientras se evidencia la brecha digital existente.

Cabe preguntarnos entonces ¿quiénes acceden a dispositivos y redes? EI INDEC informa: en el cuarto trimestre de 2019, el 95,9\% de las personas de entre 18 y 29 años utilizaba un dispositivo móvil para comunicarse, y el porcentaje subía al 98,5\% de los que estaban cursando una carrera de nivel terciario o universitario (INDEC, 2019)(1). Durante la "nueva normalidad" se incrementó el uso de distintos dispositivos tales como teléfonos celulares, computadoras o tabletas a través de los cuales se pudo continuar a pesar de todo. Pero para quienes no cuentan con posibilidades de acceso, se profundizan las condiciones de desigualdad y dependencia. En un mundo cada vez más digitalizado, la pandemia evidenció que hay sectores que ni siquiera disponen de acceso a la conectividad. Ante esta realidad, el Gobierno Nacional decide garantizar el derecho humano de acceso a las Tecnologías de la Información y las Comunicaciones (TIC) y el 21 de Agosto del 2020 declara "servicio público" a los servicios TIC, (DNU) N690/2020(2). El decreto determina que los licenciatarios y las licenciatarias de los servicios de las Tecnologías de la información y las comunicaciones (TIC) fijarán sus precios, los que deberán ser justos y razonables, deberán cubrir los costos de la explotación, tender a la prestación eficiente y a un margen razonable de operación.

El decreto también prevé la regulación de precios de los servicios, esto provocó un descenso en el precio de las acciones de empresas como Telecom Argentina (TECO2) y Cablevisión Holding $(\mathrm{CVH})$. Con el transcurso de los días, otras empresas del sector comenzaron a realizar declaraciones y reclamos sobre la decisión del ejecutivo. A principios de septiembre del mismo año en la jornada "El futuro de las comunicaciones en la Argentina" (3)los directivos de Telefónica de Argentina, Telecom, Claro y DirecTV, expresaron en conjunto el rechazo al DNU. Posteriormente, se sumaron Supercanal y Red Intercable advirtiendo por la caída en las inversiones y la calidad de los servicios de Internet y televisión por cable.

Una vez más, las disputas de sentidos, de poder de propiedad de las tecnologías vulnera el derecho a la conectividad. El acceso a la conectividad y en realidad la conectividad y el acceso a servicios tics abre puertas a otros derechos y a otros accesos. Los servicios de 
comunicaciones garantizan la polifonía de voces y perspectivas, es un potencial que podrían incluirse orgánicamente en el campo de la educación, de la producción del conocimiento, del periodismo, de las prácticas ciudadanas, las mediaciones y la participación. También los consumos culturales, la capacitación, trabajo y a la producción. ¿Qué estrategias podremos generar desde la Universidad Pública para garantizar la conectividad?

Paula Inés Porta - Universidad Nacional de La Plata - Doctora en Comunicación. Docente, Investigadora y Extensionista. Directora de Question/Cuestión. Integrante de IICom (Instituto de Investigaciones en Comunicación) FPyCS UNLP.

\section{Notas}

(1) INDEC- EPH Ciencia y Tecnología (2019). Acceso y uso de tecnologías de la información y la comunicación - Cuarto Trimestre. Ciudad de Buenos Aires: https://www.indec.gob.ar/uploads/informesdeprensa/mautic 05 19CF6C49F37A.pdf.

(2)https://www.boletinoficial.gob.ar/detalleAviso/primera/233932/20200822

(3) http://convercom.org/ 
La pandemia de la desigualdad. Acerca de la comunicación y las brechas de género.

Malvina Eugenia Rodríguez.

malvirodriguez@gmail.com

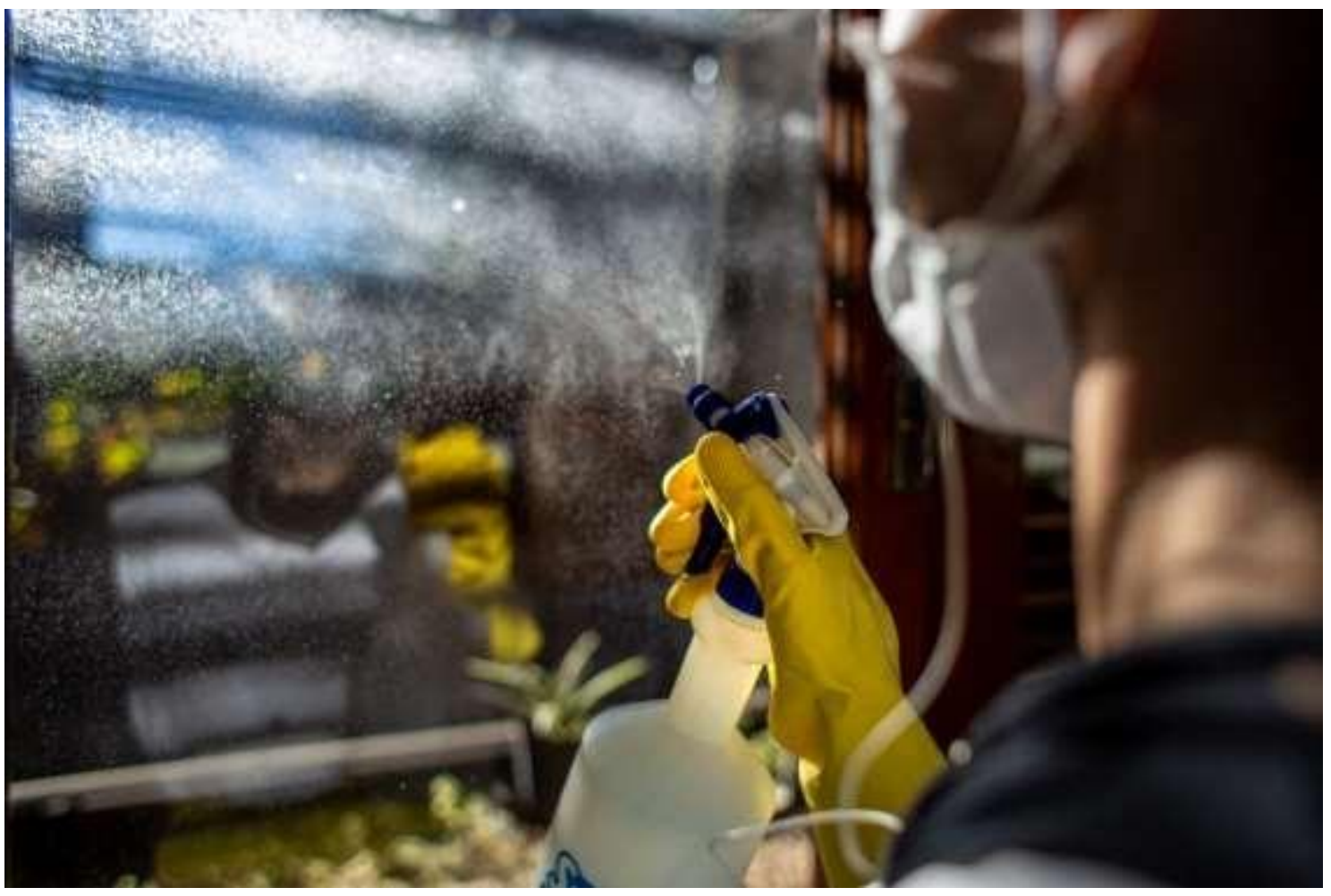

La foto, que corresponde a la Revista Ardea de la Secretaría de Comunicación Institucional de la UNVM: https://ardea.unvm.edu.ar/ensayos/trabajo-domestico/

La pandemia del covid-19 visibilizó otras pandemias históricas de nuestro mundo, como las desigualdades sociales, y especialmente las de género e informacionales. El desafío de una política comunicacional que combata las brechas se basa en la construcción de una comunicación pública como derecho humano. 
Las desigualdades son la pandemia más antigua de la humanidad. Presentes y únicas en su permanencia, como esas fotos de cámaras analógicas que desempolvamos de algún cajón de recuerdos, así se apilan las inequidades, los desequilibrios y las brechas, tanto entre los países ricos y pobres como en el interior de los mismos. El Covid-19 vino a recordarnos que la materialidad del mundo pende de un hilo entre tanta vorágine de redes digitales y desarrollos tecnológicos.

La acumulación desmedida de la riqueza por el capitalismo financiero internacional coloca a amplios sectores de la población mundial entre la pobreza y la miseria, la aprisiona en los márgenes de la inseguridad y la desesperanza. En ese contexto, la brecha tecnológica se convierte en un cráter imposible de cerrar. ¿Qué puede ofrecer a quienes no tienen las necesidades básicas satisfechas el desarrollo de la inteligencia artificial, la robótica o de los entornos digitales?

La violencia de género es la otra pandemia por la que debería detenerse el mundo. Un problema que más que social es político, en cuanto implica una redistribución del poder, de los privilegios y responsabilidades asociados a ese poder. Las consignas feministas hablan del hartazgo ante la impunidad del criminal y, a la vez, son la muestra de un movimiento social cuya vocación de lucha y transformación no fue acallada ni siquiera en el contexto de emergencia sanitaria.

En esta humanidad, atravesada por la injusticia social, las luchas de los movimientos feministas y de los colectivos de diversidades sexuales constituyen la otra cara de la moneda del modelo bioeconómico del patriarcado: solo desde la reformulación profunda de las relaciones entre géneros, de las políticas de cuidado, de las lógicas de organización social heteronormativas, de las estructuras de producción neoliberales y, sobretodo, de las formas de conducción política misóginas, se podrá pensar en una sociedad más justa.

¿Qué ocurre en el ámbito de la comunicación socio-digital? Las brechas materiales se producen y reproducen a partir de las brechas discursivas que construyen los andamiajes de la comunicación hegemónica, la de los mass media que responden a los poderes económicos transnacionales y la de las arquitecturas de los social media y otros entornos digitales hiperconcentrados en un ecosistema cada vez más paradójico en su lógica de apertura y cierre. 
El universo comunicacional, sin embargo, no se reduce a las redes digitales o a los medios de comunicación masivos. Las redes de militancia sociodigital, como lo muestran los movimientos feministas, surgen de o construyen comunidades identitarias, donde el encuentro interpersonal resulta fundamental para la construcción de sororidad. Más allá de la calle y de la pantalla, la complicidad feminista se ha convertido en un discurso que se respira en diferentes ámbitos e instituciones, que circula como un guiño de pertenencia, donde los ejes semánticos de la lucha contra la injusticia histórica están en las palabras y en los pañuelos. Las mujeres y las diversidades sexuales se (auto)reconocen en el espacio público, en el social y en el privado, se reúnen en los gritos y en los silencios. Y eso resulta un arma poderosa por su alcance tanto manifiesto como latente.

El debate reciente sobre las políticas comunicacionales en América Latina son el reflejo de esos dos mundos, de esas brechas convertidas en "grietas": o se libera el mercado de medios masivos y digitales, o se establecen criterios de regulación que aseguren el ejericio de la comunicación como derecho humano. Para todas, todos y todes.

Malvina Eugenia Rodríguez. Dra. en Ciencias Sociales. Mgter. en Relaciones Internacionales. Lic. en Comunicación Social. Docente e investigadora de la Universidad Nacional de Villa María 


\title{
Desigualdad y pobreza en Salta: cómo impactó la pandemia en los sectores populares
}

\author{
María Natalia Saavedra \\ natalita1409@gmail.com \\ (ICSOH-CONICET / INCOPOS-UNSa)
}

El contexto de emergencia evidenció la precariedad -que ya existía y que se agudizó por la pandemia- de muchas familias pertenecientes a un sector social subalternizado y marginalizado de la ciudad de Salta.

La situación crítica de los sectores populares en Argentina se profundizó debido al Covid-19, lo que impactó de manera negativa en el ejercicio de los derechos de estos grupos vulnerables. En este sentido, Ixs ciudadanxs debieron adaptarse a las nuevas condiciones de vida que implicaban dicho entorno particular, pero con el paso del tiempo se pudo observar que la realidad de esta parte de Salta estaba signada por la desigualdad y que distaba de la situación vivida por las clases medias y altas. Es decir que se pusieron de manifiesto las profundas desigualdades que ya existían en nuestras sociedades y que en este periodo se fueron agravando. Si bien el estado generó acciones de contención, esto no fue suficiente para garantizar el bienestar de la totalidad de estos actores, quienes, identificando necesidades urgentes, decidieron desarrollar tareas comunitarias en pos del bienestar común.

Se puede decir entonces que, estas problemáticas se vieron interpeladas por el contexto de emergencia, por lo cual se generaron desde el gobierno, universidades, entidades, tareas de monitoreo de las condiciones de vida de los hogares, de las condiciones económicas, productivas y laborales; y de las capacidades estatales frente a la crisis, lo que permitió comprender la necesidad de que los barrios vulnerados sean considerados como problemáticas que se debían atender y fortalecer desde las políticas públicas.

A nivel local y como parte del trabajo como cientistas sociales, se están realizando trabajos de indagación de estos nuevos procesos, con mecanismos de acercamiento y herramientas de indagación que se han tenido que reorganizar y readecuar a las condiciones de distanciamiento, a través, por ejemplo, de la virtualidad. En este marco situacional se 
considera necesario poder indagar en las diversas prácticas de organización social que se generaron con el fin de la conquista de derechos que emergieron o se fortalecieron durante la pandemia en sectores populares de nuestras ciudades.

En definitiva, se propone seguir relevando y explorando las consecuencias de la pandemia, desde la mediación con los actores, para conocer sus necesidades y así, proponer acciones para que los gobiernos generen políticas públicas más eficientes y eficaces que incluyan a todxs Ixs ciudadaxs. La tarea entonces como comunicadores es ayudar a resolver las desigualdades, acompañando y estando al servicio de la sociedad en estos nuevos procesos de transformación.

María Natalia Saavedra - Doctora en comunicación por la UNLP. Investigadora del ICOSH y del INCOPOS de la UNSa. Docente de Semiótica Audiovisual de la Licenciatura en Ciencias de la Comunicación de la FH - UNSa. 


\section{Convergencias, transmedia y democracias}

Una mirada a nuestras conversaciones sociales en la coyuntura política actual

Nadir Emanuel Secco nadirsecco@unc.edu.ar

Vivimos en una cultura de la convergencia y esa cultura tiene una forma de expresión en la política, caracterizada por la configuración de experiencias en espacios híbridos, entre lo físico y lo virtual, de encuentro, narraciones, resistencias, participaciones. Comunidades construidas no desde lo común homogéneo únicamente, sino desde las multiplicidades y heterogeneidades , potenciadas por el uso de lo tecnológico para construir una acción colectiva con impacto territorial tanto en lo físico, como en lo virtual. Así, en tiempos electorales en nuestras democracias practicamos una de las acciones más antiguas de la humanidad: conversamos.

Inmersos en una coyuntura política sin precedentes -las primeras elecciones en la pandemia más importante de la historia- las conversaciones que nos encuentran como sujetos de esta cultura de la convergencia, adquieren sentido bajo la idea de experiencias narrativas transmediales.

Desde la mirada de Denis Porto Renó, Carolina Campalans y Vicente Gosciola (2012), en Narrativas Transmedia entre teorías y prácticas, la "narrativa transmedia, transmedia storytelling 0 , simplemente, transmedia no es una estrategia, una moda, una estructura. La narrativa transmedia es un lenguaje definido naturalmente por la evolución de la sociedad contemporánea" ( $p .1$ ), es un lenguaje narrativo que nos ofrece una posibilidad de navegación por contenidos, en diferentes plataformas, territorios y/o interfaces, que son complementarios entre sí y constituyen una forma experiencial con un sentido común y de múltiples 
interpretaciones. Hacemos, pensamos, nos encontramos y relacionamos, desde diversas formas narrativas participativas. Esa forma cobra este momento histórico en nuestro país.

En cada elección hay una necesidad de conversación, de abrir la discusión, de encontrarse(nos) con otros. Esas conversaciones se construyen en diversos territorios, con diversas estrategias que convergen con un sentido común: ganar la confianza que se materializa en el voto. Para eso, dentro del gran universo transmediático electoral, productores de contenidos -partidos políticos- nos cuentan historias, construyen experiencias narrativas, en una multiplicidad de lenguajes. En su gran mayoría nos encontramos frente a estrategias que replican la lógica de la Sociedad de Masas, un discurso one to many. Sin embargo, la cultura de las convergencias nos permite intervenir en ese proceso como partícipes de la conversación. Esas intervenciones tienen diferentes intenciones territoriales, pero guardan consigo una característica: por un instante todos y todas, de una manera u otra, estamos involucrados en una conversación sobre una acción del presente que define una parte de nuestro futuro y en la que intervenimos desde nuestra producción de sentido.

El mundo narrativo del que participamos como ciudadanos -nuestra democracia representativa, republicana y federal- funciona como una de las construcciones simbólicas más fuertes de nuestros acuerdos de convivencia como sociedad. La democracia le da sentido a la participación, la habilita, la define, establece marcos y nos involucra a todos los participantes. Una dimensión construida por la narrativa, con definiciones de espacios y tiempos, que genera una especie de imagen mental en los/as usuarios/as que participan de la experiencia transmedia. Un mundo construido por la narrativa, "constructos imaginarios compartidos por la audiencia de culto con un interés en el universo" (Klastrup y Pajares Tosca, 2004: 5).

En ese mundo, siguiendo a Carlos Scolari (2013), encontramos algunas características que lo definen, específicamente tres: lugar, tiempo y personajes. Un lugar, porque toda narrativa transmedia debe construir o establecer una ubicación espacial, un aquí; un tiempo, entendiendo que ese mundo narrativo desarrolla un orden temporal en el que transcurre la historia. Finalmente, personajes que son quienes desarrollan las acciones y hacen mover el relato. Un lugar: nuestro país, nuestras provincias, nuestras ciudades y pueblos. Un tiempo: septiembre de 2021. Personajes: la democracia tiene muchos, aunque en esta coyuntura 
electoral aparecen apuntalados/as candidatas y candidatos de las diferentes fuerzas políticas, y electores (les participantes) de la fiesta democrática, de esta gran experiencia transmedia.

Construimos esa conversación desde nuestras participaciones en el mundo físico y virtual. Expandimos contenidos, consignas, universos que generan nuevas significaciones. Tomamos la conversación política como productores de contenido y como ciudadanos de una cultura de la convergencia. De esta manera la participación se consolida como una característica sustancial de la experiencia democrática que asume la forma de experiencia narrativa transmediática. Las participaciones transforman el entorno en el que existimos, nos involucra como sujetos sociales, nos invita a construir con otros y aprender del intercambio y el diálogo.

Este fenómeno cada vez más característico de la época de elecciones en Argentina -y entendemos que en gran parte de las democracias del mundo- nos invita a ser parte de un gran universo narrativo, siempre en modo presente, que trasciende barreras espaciales y en donde cada uno de nosotros, como ciudadanos y prosumidores de esta cultura digital, participamos activamente en al conversación, cargando de sentido e ideales sobre nuestro futuro en cada uno de los intercambios.

Sin dudas, estamos en presencia de un lenguaje para la democratización. Decimos y escuchamos, y en ese ejercicio nos constituimos en ciudadanos: actores activos en estos procesos que pone en valor el intercambio y la reflexión. De consumidores, pasamos a públicos, de públicos pasamos a ciudadanos, en una transformación, una metamorfosis, que existe porque se habilita en el juego de la democracia política. Aparecemos como prosumidores ciudadanos, participantes de la conversación política. Una especie de prosumidor particular, que opera desde el consumo cultural, la reproducción e intervención de contenidos, con un sentido político y social. En ocasiones una expresión de las individualidades, pero que en el universo de la conversación representa una experiencia colectiva que toma esa individualidad interactiva, pero la hace jugar en el orden de una comunidad imaginada, organizada, que alimenta un proceso político y comunicacional para construir más democracia. 
La comunicación transmedia puede ser el lenguaje que nos proponga otra posibilidad para articular cambios, proponer evoluciones y acercar la práctica política con mayor facilidad, potenciando la conversación como encuentro de la democracia y modificando la interfaz "Elecciones". Que sea de esa manera depende de una serie de variables, con una centralidad en nuestro ejercicio ciudadano.

\section{Referencias bibliografícas}

Ardini, C. y Caminos, A. (2018). "Manual para experiencias transmedia sociales: Contar (las) historias". Córdoba, Argentina.

Porto Renó, Denis (2012) "Narrativas Transmedia. Entre teorías y prácticas”. Bogotá: Editorial Universidad del Rosario. 252 p. (Colección Textos de Ciencias Humanas).

García Carrizo, J. y Heredero Díaz, O. (2015). "Propuesta de un modelo genérico de análisis de la estructura de las narrativas transmedia". Icono 14, volumen (13), pp. 260-285. doi: 10.7195/ri14. v13i2.745

Jenkins Henry (2008) "Convergence Culture. La cultura de la convergencia en los medios de comunicación". Buenos Aires. Paidós

Klastrup L. y Pajares Tosca Susana (2004). "Transmedial Worlds - Rethinking Cyberworld Design". ISBN: 0-7695-2140-1.

Scolari, Carlos (2013) "Narrativa Transmedia cuando todos los medios cuentan". Barcelona, España. Deusto S.A. Ediciones.

Nadir Emanuel Secco. Docente - Investigador Facultad de Artes UNC - Maestrando en Comunicación Digital Interactiva UNR - Nodocente Centro de Promoción y Producción Audiovisual UNC 
La otra epidemia, la desinformación. El rol de los medios y los comunicadores frente a la pandemia

Pani Toledo

panitoledo@gmail.com

twitter.com/PaniToledo

facebook.com/pani.toledo/

instagram.com/panitoledo

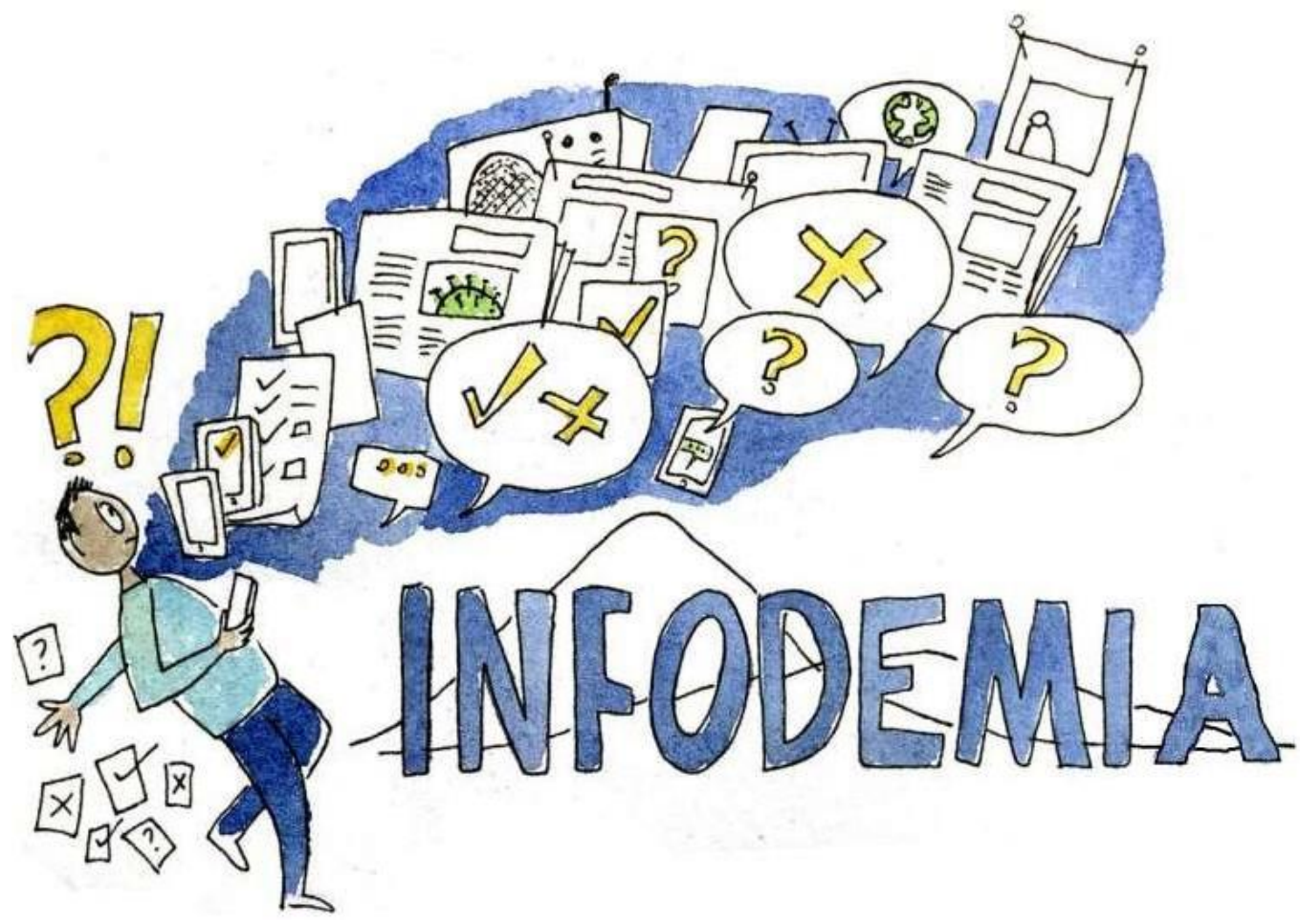


Fuente: REC https://www.infobioquimica.com/new/2020/05/11/informacion-oportuna-y-precisapara-disipar-la-infodemia/

Además de la epidemia de una enfermedad, hay una segunda epidemia, la de la desinformación. Una epidemia propagada por agentes infecciosos de bits, y se transmiten mediante las redes. Y, por ende, la desinformación sobre el virus viaja a la velocidad de un tuit.

¿Qué es la desinfodemia? La desinfodemia es la propagación de una enfermedad facilitada por desinformación viral. Esto parecería estar pasando con la información en la pandemia del coronavirus.

La idea de doble epidemia, a nivel agente infeccioso y a nivel desinformación, no es nueva. Lo que es quizá más reciente es considerar que estas dos epidemias simultáneas se potencian mutuamente, por lo que el daño total termina siendo más que la suma de las partes. Estos mundos, que parecen separados, empiezan a interactuar con efectos que recién ahora estamos empezando a entender.

De esta manera el contagio emocional, facilitado por la las noticias falsas y la propagación por las redes sociales puede erosionar la confianza en, por ejemplo, las vacunas y volverlas discutibles. En las redes sociales, el diluvio de información contradictoria, desinformación e información manipulada debería ser reconocido como una amenaza global a la salud pública.

La difusión de datos (ya sean información o desinformación) ya no sigue el tradicional camino de emisores/receptores. Las redes permiten una enorme y riquísima trama de conexiones horizontales, comunicación de noticias, memes, opiniones y aun mensajes personales. Por lo que cada uno de nosotros, al convertirse, al menos parcialmente, en emisor, también se vuelve responsable en este proceso de desinfodemia.

Como con las enfermedades, se puede ser un portador sano que, sin ser afectado, transmite el agente infeccioso a los demás. Muchos medios, quizás intentando imitar el éxito de 
las redes sociales, adoptan su tono apocalíptico y acrítico, y a veces son poco rigurosos con la veracidad de un contenido, porque priorizan la primicia.

En un contexto de desinfodemia, es crucial lograr y conservar una comunicación adecuada. La mejor comunicación, en términos sanitarios, no es solamente la que informa, sino también la que ayuda a generar los comportamientos necesarios para prevenir, enlentecer 0 frenar la enfermedad.

El desafío es cómo comunicar en temas de salud sin generar desinfodemia: ni minimizar, ni generar ansiedad y pánico. Los mensajes deben ser claros, completos y sencillos de comprender. Esto incluye poder explicar la complejidad, el riesgo para uno y para los demás, y las acciones que hay que seguir.

El emisor/comunicador de la información debe ser transparente y confiable, cuidar la credibilidad es clave, porque sin confianza no hay comunicación efectiva.

Pani Toledo - Licenciado en Comunicación Social. UNR y Magister en Comunicación Social, Universidad Diego Portales. Profesor Titular de Comunicación Estratégica y de Producción y evaluación de materiales multimedia. Docente de posgrado. Investiga temas relacionados a los nuevos medios y las ciberculturas. 


\section{Experiencia desde la Lic. en Comunicación Social de la Universidad Nacional de San} Juan

Cecilia Vila

ceciliavila08@gmail.com

Dentro de todo el contexto que nos atraviesa, y que ha promovido grandes cambios en nuestra vida académica cotidiana, parte de las reflexiones que vamos haciendo con los/as estudiantes y los/as compañeros/as docentes están principalmente orientados a las transformaciones por las mediaciones tecnológicas. Son de procesos de enseñanzaaprendizaje que estábamos acostumbrados/as a vivenciarlos en la presencialidad del espacio físico de la Universidad Pública y desde la pandemia de Covid 19 empezamos a reconstruirlas, readaptarlas y por lo tanto resignificarlas en el nuevo escenario con las herramientas que en parte reemplaza eso.

De esta manera en la experiencia colectiva del dictado de las asignaturas, en el ciclo lectivo 2020 y lo que llevamos del 2021, tanto docentes como estudiantes hemos aprendido el uso de las herramientas digitales diseñadas para educación a distancia. Hasta el año 2019, la Universidad Nacional de San Juan aún no expandía en todo su potencial el sistema SIED y la pandemia aceleró su uso. Con estas nuevas posibilidades aprendimos el uso de la conferencia por plataforma para encuentros sincrónicos y múltiples herramientas dentro de las aulas virtuales para trabajar de modo asincrónico. Hicimos cambios en algunas consignas de trabajos prácticos y parciales, alternando ejercicios de escritura académica con exposiciones en la plataforma, análisis de corpus audiovisuales que tomaran temáticas de los contenidos de la materia, en lo que concierne a investigación social y en comunicación y producción discursiva mediática. Los propósitos estuvieron enfocados a potenciar otras aptitudes y capacidades en el espacio de pedagógico, así como también aliviar la carga de lecturas teniendo en cuenta que todo su cursado sería de esta manera. Nuestra experiencia personal fue enriquecida ya que nos apoyamos en las redes federales con docentes de otras universidades que ya venían 
trabajando con educación a distancia en intercambios que nos dieron herramientas y contención ante la magnitud de nuevo y desconocido.

Me parece que toda esta situación nos deja, en una primera fase, más preguntas que certezas. Asimismo, para el campo de investigación de la comunicación se abre una nueva posibilidad de construir lo vivenciado hasta ahora como objetos de estudio para las prácticas de comunicación y mediatización en la producción social del sentido. Creo que esto nos puede llevar mucho tiempo comprenderlo e investigarlo, pero es necesario.

En lo que respecta a la producción discursiva, nosotros desde las asignaturas, en el espacio de las clases, hemos podido hacer algunas aproximaciones de lecturas semióticas sobre imágenes, narrativas y metáforas construidas en el primer período de la pandemia desde los medios de comunicación. Paralelamente, hemos podido problematizar nuevamente el tema de acceso a la información pública y apropiación de las TIC, cuando hay un período de confinamiento tan fuerte, en el marco de la comunicación como derecho humano. Son temas que, afortunadamente, en el primer año de pandemia pudimos apreciar su trascendencia con más fuerza más allá de los debates académicos y de las organizaciones sociales que trabajan estas problemáticas desde hace muchos años. Han podido ocupar otros espacios de la esfera de lo público como pueden ser las agendas mediáticas y agendas políticas y del estado. Por lo tanto, es un contexto propicio para seguir discutiendo lo que hace unos años viene sosteniendo la Coalición por una Comunicación Democrática en tanto acceso, participación, pluralidad y diversidad para el sistema de medios de radiodifusión e internet.

De modo remoto, e incluso siendo parte de diferentes brechas en el acceso a la conectividad hemos podido reflexionar esto en las asignaturas. Qué sucede desde el polo de las emisiones discursivas, principalmente, mediáticas, cómo estamos reconociendo esos nuevos sentidos de lo pandémico, la salud, la enfermedad, el contacto humano y lo social.

En cuanto a los proyectos de investigación y los asesoramientos que nos tocan a las tesinas de investigación de la Licenciatura en Comunicación Social de la UNSJ buena parte del trabajo de este año fue repensar las estrategias metodológicas y los objetivos cuando hay un escenario emerge, y no previsto como este. Esto nos lleva a promover reflexiones que puedan incluso implicar construcciones de categorías para abordar con más complejidad su trabajo de 
campo. Pensemos que muchas de las técnicas de recolección de datos están más diseñadas desde la promoción de procesos de mediación y ahora pueden ser resuelto, algunos, con intervenciones tecnológicas. El acceso limitado a la territorialidad hace reconfigurar la estrategia y la mirada hacia el objeto.

Como pensamiento final, consideramos que ante el nuevo escenario queda aún más claro por qué seguir trabajando la comunicación como derecho humano.

Cecilia Vila - Docente en las asignaturas Semiótica y Comunicación y Metodologías de la Investigación en Comunicación de la Lic. en Comunicación Social de la Facultad de Ciencias Sociales de la Universidad Nacional de San Juan. 